\title{
Review on Spinning of Biopolymer Fibers from Starch
}

\author{
Selamu Temesgen ${ }^{1,2,3, *}$, Mirko Rennert $^{1}{ }^{(D)}$, Tamrat Tesfaye ${ }^{2}$ and Michael Nase ${ }^{1}(\mathbb{D}$ \\ 1 Institute for Biopolymers and Sustainability (ibp), Hof University of Applied Sciences, \\ 95028 Hof/Saale, Germany; mirko.rennert@hof-university.de (M.R.); michael.nase@hof-university.de (M.N.) \\ 2 Ethiopian Institute of Textile and Fashion Technology, Bahir Dar University, Bahir Dar P.O. Box 1037, Ethiopia; \\ tamrat_tsfy@yahoo.com \\ 3 School of Textiles, Kombolcha Institute of Technology, Wollo University, Kombolcha P.O. Box 208, Ethiopia \\ * Correspondence: stemesgen@hof-university.de; Tel.: +251-91-344-5090
}

Citation: Temesgen, S.; Rennert, M.;

Tesfaye, T.; Nase, M. Review on

Spinning of Biopolymer Fibers from

Starch. Polymers 2021, 13, 1121.

https://doi.org/10.3390/

polym 13071121

Academic Editor: George

Z. Papageorgiou

Received: 19 February 2021

Accepted: 20 March 2021

Published: 1 April 2021

Publisher's Note: MDPI stays neutral with regard to jurisdictional claims in published maps and institutional affiliations.

Copyright: (c) 2021 by the authors. Licensee MDPI, Basel, Switzerland. This article is an open access article distributed under the terms and conditions of the Creative Commons Attribution (CC BY) license (https:/ / creativecommons.org/licenses/by/ $4.0 /)$.

\begin{abstract}
Increasing interest in bio-based polymers and fibers has led to the development of several alternatives to conventional plastics and fibers made of these materials. Biopolymer fibers can be made from renewable, environmentally friendly resources and can be fully biodegradable. Biogenic resources with a high content of carbohydrates such as starch-containing plants have huge potentials to substitute conventional synthetic plastics in a number of applications. Much literature is available on the production and modification of starch-based fibers and blends of starch with other polymers. Chemistry and structure-property relationships of starch show that it can be used as an attractive source of raw material which can be exploited for conversion into a number of high-value biobased products. In this review, possible spinning techniques for the development of virgin starch or starch/polymer blend fibers and their products are discussed. Beneficiation of starch for the development of bio-based fibers can result in the sustainable replacement of oil-based high-value materials with cost-effective, environmentally friendly, and abundant products.
\end{abstract}

Keywords: bio-based materials; biofibers; biopolymers; oil-based polymers; starch; spinning

\section{Introduction}

The effects of oil-based plastics and additives on climate, water and soil quality are omnipresent. In the last few decades, many scientific studies and developments have been undertaken in order to manufacture products sustainably from renewable raw materials and thus reduce the dependence on fossil raw materials and the global amount of microplastics. Textiles based on synthetic fibers are supposed to be one of the biggest sources for microplastic due to washing abrasion and the contamination of wastewater. The world fiber market accounted for the largest percentage of synthetic fibers by the early 2000s, which has increased rapidly in comparison to 5\% in 1960 [1]. Before the usage of synthetic polymers, the major sources of fibers were cotton, wool, and silk. The market share of cotton fiber dropped from $81 \%$ to $39 \%$ over the last century due to high demand for synthetic fibers [1]. Excessive dependence on oil-based polymers has negative impact, because the sustainability of synthetic materials is limited by natural oil deposits. The production and disposal of oil-based polymers causes environmental pollution. The need to use bio-based materials to substitute synthetics becomes more relevant for the demand to a circular bio-economy.

Biopolymers or bio-based polymers are renewable, environmentally friendly and biodegradable materials, which can be used as an ideal substitute for oil-based polymers that are synthetic in nature [2]. The increasing demand in bio-based polymers/biopolymers has brought an endeavor to develop several alternatives to synthetic materials or synthetic polymers [3]. One of the interesting alternatives to synthetic materials/polymers is the use of natural raw materials such as starch, lignin, keratin, chitosan, gelatin, collagen, and cellulose for biopolymer synthesis. Starch is a naturally abundant biopolymer and has 
the potential for mass commercial use. Starch has often been used as a food ingredient, although it has become a good alternative for industrial applications in areas such as paper, pharmaceuticals, and textiles [4].

Starch is the predominant carbohydrate reserve in many plants such as potato, tapioca, and cornstarch [5]. Starch has a semicrystalline morphology with different degrees of crystallinity. It consists of two major components: amylose, mostly linear $\alpha\left(1 \_4\right)$ glucan linkage; and amylopectin, an $\alpha\left(1 \_4\right)$ glucan linkage which has $\alpha\left(1 \_6\right)$ linkages at the branch point [6]. The association of hydroxyl groups among the different molecules has brought on different properties of the two forms of starch, form (1) amylose and form (2) amylopectin (see Figure 1). Structurally, amylose is linear with $2-5$ relatively long branches and the branches have average polymerization degrees of about 350 monomer units. The average molecular weight of linear amylose molecules is from $0.2-2$ million $\mathrm{g} / \mathrm{mol}$, while the molecular weight of branched amylopectin molecules is as high as 100-400 million $\mathrm{g} / \mathrm{mol}$ [7].

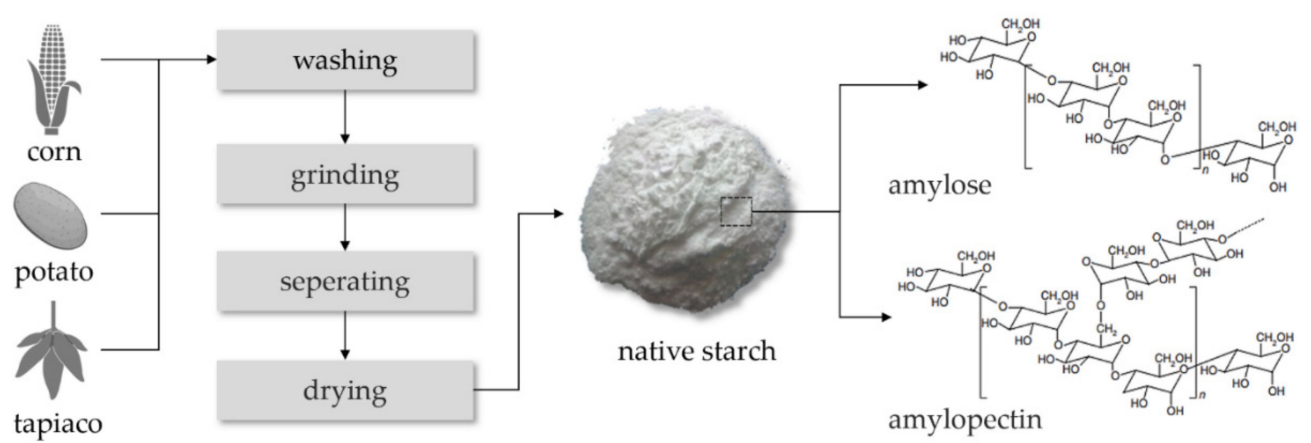

Figure 1. The process of destructured native starch from bio-based resources and the structure of starch with amylose and amylopectin.

The linear nature of amylose can facilitate the orientation and parallel alignments of hydroxyl groups. The occurrence depends on the conditions for macromolecular chain mobility, particularly by dilution with suitable solvents in most cases. Alternatively, dilution under high temperatures can be applied. By aligning neighboring amylose molecules, the intermolecular interactions can be influenced by the formation of hydrogen bonds. The average polymerization degree of the macromolecular branches in amylopectin molecules is about 25 monomer units. Amylopectin molecules have limited chain mobility and do not align and associate spontaneously due to the highly branched structure of these molecules [7]. Figure 1 illustrates the schematic structure of amylose and amylopectin in starch.

Starch without additives is a biodegradable, non-toxic polymer with excellent biocompatibility, but hardly processable without plasticizers due to its complex macromolecular structure and thus limited ability to react to external deformations [8]. Starch is an abundantly available biomass which is capable of substituting synthetic polymers. Starch in its native form has some limitations related to its mechanical properties (modulus, fracture toughness) and thermal stability [5,9]. Researchers have developed methods to minimize the limitations of starches in order to improve their properties for industrial application [9]. Various processes including plasticization, and physical, chemical enzymatic and genetic modification have been studied [10]. As a conclusion, blends of starch and other biodegradable polymers have been identified as the most promising way to minimize the limitations of native starches to develop blends of starch and biodegradable polymers to obtain materials with a wide range of application [11].

Many biopolymers have been used to form fibers using different spinning techniques [5]. Fiber-reinforced polymer composites have been used as lightweight solutions for commercial industries because of their versatility and specific properties. They have been regarded as advantageous over traditional engineering materials, such as steel or aluminum. The demand for composites is expected to increase from GBP 2.5 billion in 2015 
to GBP 10 billion in 2030 in the United Kingdom [12]. Contemporary life cycle assessments and bioeconomic strategies consider local bio-based resources, and carbon sequestration at end-of-life of a product by recycling or targeted degradability if needed.

Starch was identified as an appropriate substitute for the polyester fiber production. Advantages of starch-based fibers are the global availability and low cost of starch, its biodegradability, and potential for a sustainable production [13]. Besides the abovementioned advantages, starch has functional advantages compared to synthetic polymers. It has a better hydrophilicity, biocompatibility, bio-absorbability, and full compostability.

Very few reports have been written about starch-based fiber spinning, focusing only on electrospinning. Further literature is available only on patents, describing the applications of different fiber spinning technologies. In this report, we review the possibilities of various spinning techniques that could be used in the production of bio-based fiber from virgin starch and starch/polymer blends and fibers produced thereof. Bio-based fibers can result in the sustainable replacement of oil-based high-value materials with cost-effective, environmentally friendly, and abundant products. Therefore, this paper is expected to be good source of information for those working with the fabrication of fibers from starches and starch/polymer blends.

\section{Starch as a Source of Fiber}

Starch is one of the most important renewable resources and is considered as the second largest source of biomass on earth after cellulose [14]. The major sources of starch are maize, rice, wheat, potato, cassava, yams, and sorghum [15]. Starch-based fibers have been fabricated mainly by blending native or modified starches with polymers, plasticizers, cross-linkers, or other additives [16,17]. Additionally, more recently, native starch has also been spun into fibers using different spinning technologies [17-19]. Spinning has a long tradition and is supposed to be the best method for continuous fiber production. The first starch-based fiber application was made using amylose. In this attempt to spin fiber from starch, it was assumed that the linear character of starch macromolecules built side-by-side associations with the amylose monomers under favorable conditions. In 1970, Barger et al. developed a method to produce amylostic filaments and fibers. These researchers developed a method of producing amylostic filaments and fibers having unique physical properties for various technical applications. The method used by these researchers is forming a physical mixture of amylostic solids and controlled amount of water and then subjecting this mixture to higher temperatures and pressures in order to form a jelly-like plastic mass. From their work, it was demonstrated that they successfully extruded the plastic mass into filaments having desirable characteristics of strength, flexibility, and water solubility.

Hiemstra and Muetgeert [18] established a continuous process for the extrusion of adjusted amylose. The extrusion was carried out on a watery sodium hydroxide solution with concentrated ammonium sulfate having a concentration greater than $30 \mathrm{wt}$ \% in the coagulation bath. The ammonium sulfate used in this process was later removed by washing. In another study, a Viscose spinning machine was utilized for spinning amylose fibers from starch [20]. In this study, $5 \% \mathrm{NaOH}$ watery starch solution was put into a coagulating bath together with sulfuric acid and sodium sulfate at $50{ }^{\circ} \mathrm{C}$. Kunz demonstrated the possibility of spinning amylose fibers, but the claimed caustic amylose composition failed to produce fibers with sufficient tensile strength. In another recent patent by Zussman et al. [19], highamylose starch-formate was electrospun into fibers. According to these researchers, the method comprises two essential steps: the demonstration of a first spinning dope, which comprises a solution or dispersion of starch in a solvent with at least $50 \%$ vol. formic acid and the right amount of starch above the critical entanglement concentration, where starch fibers are supposed to be produced; and secondly, the electrospinning dope to produce a starch-formate fiber.

Spinning amylose suffered from different disadvantages such as insufficient fiber tensile strength and cost-intensive adjusted amylose from starch composition, because 
starches have a higher content of amylopectin [17]. Studies are available on various methods of fiber spinning from starch compositions containing both amylopectin and amylose components $[18,19]$. Spinning fibers from starches generally consisted of two categories of starch compositions, namely thermoplastic starch composition (TPSC) and non-thermoplastic starch compositions (NTSC).

\subsection{Fiber Spinning from Thermoplastic Starch Compositions}

Thermoplastics are uncrosslinked polymers and have a low-viscous flow once heated above a specific melting temperature $T_{m}$ and become hard when they are cooled below $T_{m}$ with a complete chain immobility if cooled under the glass transition temperature $T_{g}$. Thermoplastics can undergo plastic deformation due to their large molar mass, entanglements, intra- and intermolecular interactions, and chain branches. The morphology of thermoplastics can be fully amorphous (only $T_{g}$ ) or semicrystalline with $T_{g}$ and $T_{m}$ [21]. Amorphous thermoplastics include mostly translucent plastics, which have a high-entropic molecular structure with a sharp softening point. Amorphous thermoplastics have isotropic rheological properties and a better dimensional stability without shrinkage, good impact resistance, and poorer fatigue resistance compared to semi-crystalline plastics. Amorphous thermoplastics also tend to have lower chemical resistance due to higher free volume and lower tough bonds, such as in semi-crystalline polymers. The characteristics of semicrystalline thermoplastics is that they have highly ordered molecular structures with sharp melting points, unlike amorphous thermoplastics. Due to the phase boundaries between amorphous and crystalline areas, semi-crystalline polymers appear rather opaque.

Thermoplastic starch can have both an amorphous or semi-crystalline morphology, containing gelatinized or destructured starch in the presence of plasticizers. Fed into an extruder with external heat and applied shear forces of screw-barrel interactions, thermoplastic starch can be molded into plastic products. It can be repeatedly melted and hardened, allowing its processing in common techniques used in the plastic industry. Starches are not truly thermoplastic in nature, which means they have no thermoplastic character in their native form [22]. In the presence of plasticizers such as water, glycerol, sorbitol, etc., at high temperatures above $90^{\circ} \mathrm{C}$ and under shear forces, starch can start to melt and flow, which makes it usable for injection molding, extrusion, or blow molding, similar to most conventional synthetic thermoplastic polymers [23]. Figure 2 shows the differences between the morphology of typical starch before and after plasticization with glycerol of different amounts.

Thermoplastic starch (TPS) composition is a translucent amorphous polymer with comparable properties to conventional polymers. It is obtained by compounding native starch with suitable plasticizers at starch gelatinization temperature. Hydrogen bonds present in native starch will be weakened by this operation which leads to fully amorphous material. The resulting material is known as plasticized starch, destructured starch or thermoplastic starch (TPS) [22-24]. It can be fully amorphous (TPSA) or semi-crystalline (TPSC). 

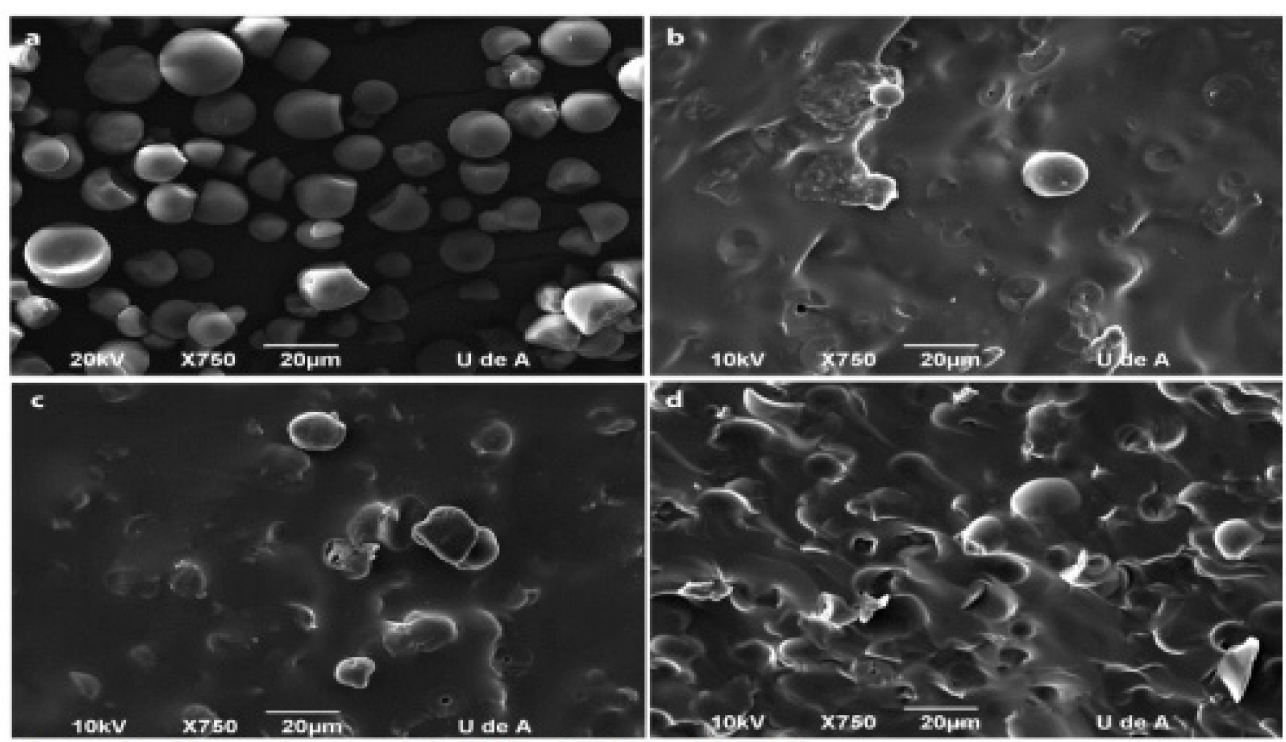

Figure 2. SEM micrographs of the starch and thermoplastic starch (TPS): starch (a), TPS30 (b) TPS40 (c) and TPS50 (d). Reprinted with permission from ref. [25]. Copyright 2018 Universidad Nacional de Colombia.

Attempts to spin thermoplastic starch compositions dates back to 1951. At this time, wet spinning technology was used to extrude the composition of aqueous starch dispersion and glycerol in a methanol/glycerol coagulation bath to obtain starch fibers [10]. The work by Buehler et al., given in U.S. patent Nos. 5516815 and 5316578, describes the application of thermoplastic starch compositions to make starch fibers using melt-spinning processes [26]. In this study, the melted thermoplastic starch was extruded through a spinneret to produce filaments. The filaments were subsequently drawn down mechanically or thermo-mechanically by a drawing unit to reduce the fiber diameter [27]. In another patent by Buehler et al. [10], they produced starch-containing fibers from corn starch and potato starch using different plasticizers. The starch melt-spinnable composition, which was subsequently granulated, had different proportions of starches with varying degrees of substitutions and amylose content. The fiber produced had an average tenacity of around $1.1 \mathrm{cN} /$ tex.

Usually, it is difficult to obtain sufficient properties from semi-crystalline TPSC alone for fiber spinning processes or fiber applications because of weak mechanical properties, retrogradation, and the high hygroscopic nature of thermoplastic starches TPS. Thus, fibers of TPS blends were investigated in much of the literature and patents on spinning TPSC fibers. A lot of research on the application of starch focused on blending thermoplastic starch and other synthetic polymers [16,27-30]. According to the study by Lorcks et al. [31], mixtures of thermoplastic starch from native potato starch and poly(lactic acid) (PLA), polyesteramide, and a copolyester of aliphatic diols and aliphatic/aromatic dicarboxylic acids was successfully spun into fibers. Bond et al. [29] described the preparation of high elongation multicomponent fibers from starch and other polymers in their patent. In this work, it was revealed that multi-component fibers were configured as sheath-cores, wherein the thermoplastic polymer component constituted the sheath and the thermoplastic starch component constituted the core component.

Biodegradable fibers from starch composites have been developed by different researchers. Nakajima and Taniguchi used polybutylene succinate (PBS) as the core material and a starch/polymer composite as the sheath, and successfully spun fibers [32]. Different kinds of polymers have been used by different researchers mixed with starch for fibers spinning, and the success of spinning these starch/polymer composites into core/sheath fibers was observed $[28,29]$. Some of the polymers used include Polycaprolactone (PCL), 
polylactic acid (PLA), polybutylene succinate (PBS), polyvinyl alcohol (PVA) and ethylene vinyl acetate (EVA) [18].

Most of the early attempts made in fiber spinning from thermoplastic starch composition are in the form of patents. Some of thermoplastically processable starch compositions are disclosed in U.S. patent Nos. 4900361, 5095054, 5736586 and PCT publication WO 98/40434 filed by Hanna et al. These abovementioned starch compositions do not contain the high molecular weight polymers which are essential to achieve the required melt viscosity and melt extensibility. The melt viscosity and melt extensibility are essential material characteristics used for production of fine fibers, thin films, or thin-walled foams to avoid fracture and failures [33].

A TPSC composition consisting of dextrin, a kind of destructured starch from tapioca or corn starch, and polyacrylamide (PAM) was developed by Bailey et al. [20]. These researchers used different plasticizers and used melt spinning technology for fiber spinning. These researchers claimed up to $10 \mathrm{wt} . \%$ of PAM in the starch recipe, but it was evidenced from their work that even less than $0.1 \mathrm{wt} . \%$ seemed to be working well. This TPSC composition can be extruded into fibers and films. The summaries of TPSC fiber spinning patents are illustrated in Table 1.

Table 1. Fiber spinning from thermoplastic starch composition (TPSC) [18].

\begin{tabular}{|c|c|c|}
\hline Title & Process Used & Patent and Year \\
\hline Method of making amylostic filaments and fibers & $\begin{array}{l}\text { Mixing and extrusion of amylostic solids, water and } \\
\text { glycerine at elevated temperature }\end{array}$ & $\begin{array}{r}\text { US3499074 } \\
(1970)\end{array}$ \\
\hline Starch-containing fibers, process for their production & Mixing and extrusion of composition & $\begin{array}{r}\text { US5516815 } \\
(1996)\end{array}$ \\
\hline Biodegradable fiber and non-woven fabric & $\begin{array}{l}\text { Forming the fibers and bonding by heating at moist } \\
\text { condition }\end{array}$ & $\begin{array}{r}\text { US6045908 } \\
(2000)\end{array}$ \\
\hline $\begin{array}{l}\text { Biodegradable fibers manufactured from thermoplastic } \\
\text { starch. }\end{array}$ & $\begin{array}{c}\text { Extrusion of the composition above into filaments, } \\
\text { drawing, winding, and knitting }\end{array}$ & $\begin{array}{r}\text { US6218321 } \\
(2001)\end{array}$ \\
\hline $\begin{array}{l}\text { High elongation multicomponent fibers comprising } \\
\text { starch }\end{array}$ & $\begin{array}{c}\text { Extrusion of substituted starch and polymer having } \\
\text { sheath-core configuration }\end{array}$ & $\begin{array}{r}\text { US6623854 } \\
(2003) \\
\end{array}$ \\
\hline Melt processable starch compositions & Mixing and extrusion of the composition & $\begin{array}{r}\text { US6709526 } \\
(2004)\end{array}$ \\
\hline $\begin{array}{l}\text { High elongation splittable multicomponent fibers } \\
\text { comprising starch }\end{array}$ & Mixing extrusion and highspeed spinning of composition & $\begin{array}{r}\text { US6743506 } \\
(2004)\end{array}$ \\
\hline Multicomponent fibers comprising starch and polymers & Melt spinning of the composition & $\begin{array}{r}\text { US6746766 } \\
(2004) \\
\end{array}$ \\
\hline $\begin{array}{l}\text { Bicomponent fibers comprising a thermoplastic polymer } \\
\text { surrounding a starch-rich core }\end{array}$ & Melt extrusion of composition and fiber formation & $\begin{array}{r}\text { US6783854 } \\
(2004 a)\end{array}$ \\
\hline $\begin{array}{l}\text { Compositions and processes for reducing water solubility } \\
\text { of a starch component in a multicomponent fiber }\end{array}$ & Melt spinning of the composition & $\begin{array}{r}\text { US6830810 } \\
(2004 b)\end{array}$ \\
\hline Fibers comprising starch and biodegradable polymers & $\begin{array}{l}\text { Compounding and extrusion of composition and then melt } \\
\text { spinning }\end{array}$ & $\begin{array}{r}\text { US6890872 } \\
(2005)\end{array}$ \\
\hline $\begin{array}{l}\text { Electro-spinning process for making starch filaments for } \\
\text { flexible structure }\end{array}$ & Electrospinning of a starch/polymer (PAM) composition & $\begin{array}{r}\text { US7029620 } \\
(2006)\end{array}$ \\
\hline $\begin{array}{l}\text { Rotary spinning processes for forming hydroxyl } \\
\text { polymer-containing fibers }\end{array}$ & Rotary spinning method forstarch/PVA composition & $\begin{array}{r}\text { US7655175 } \\
(2010)\end{array}$ \\
\hline Starch fiber & Melt blowing of the composition & $\begin{array}{r}\text { US7704328 } \\
(2010 \mathrm{~b}) \\
\end{array}$ \\
\hline Multicomponent fibers comprising starch and polymers & - & $\begin{array}{r}\text { US7851391 } \\
(2010) \\
\end{array}$ \\
\hline Fibers comprising starch and a crosslinking agent & Melt blowing of the composition & $\begin{array}{r}\text { US7938908 } \\
(2011)\end{array}$ \\
\hline
\end{tabular}




\subsection{Spinning Non-Thermoplastic Starch Compositions}

Non-thermoplastic starch composition (NTPSC) consists of starch and water softening to a degree that the material can be brought into a flow. This combination can be processed, e.g., by spinning, to form a plurality of non-thermoplastic starch fiber suitable for forming a flexible fibrous structure [34]. Non-thermoplastic starch composition is not processable by melt spinning, but it can be processed using wet spinning and dry spinning. There is risk of decomposition in the case of processing non thermoplastic starch using melt spinning because its degradation temperature is lower than its melting temperature. The non-thermoplastic starch composition also differs from a thermoplastic composition. The non-thermoplastic starch composition is dewatered by drying and obtains a solid state by losing its thermoplastic properties [35]. The non-thermoplastic starch fiber has no melting point because it decomposes before reaching melting temperature.

In early attempts to produce starch fibers, a wet spinning process was used principally. For example, a starch/solvent colloidal suspension can be extruded from a spinneret into a coagulating bath. Previous studies for wet spinning starch fibers include U.S. Pat. Nos. 4139699, 4853168 and U.S. Pat. No. 4234480 [35]. While spinning NTSC, some additives such as crosslinking agents can be included, in order to improve the properties of starch fibers.

Previous work conducted by Eden and Trksak [33] described the possibility of spinning high amylose starch. Some other researchers also used ammonium salt in the coagulation bath to crosslink the final starch and starch/PVA fibers. A process for the dry spinning of non-thermoplastic starch composition is described in recent patents [30]. A new spinning device was invented by Bastioli et al. [36], and in this device starch fibers are formed and coagulated as watery starch dispersions travel through the holes of tubular a wall into a coagulating chamber. The coagulation agent used was ammonium sulfate. The fiber diameter was dependent on the size of the holes, which may have narrow outlets opening 10 to $500 \mu \mathrm{m}$.

In a patent claimed by James et al. [35], an NTPSC of unsubstituted polysaccharide and PVA were spun into fibers with an average fiber diameter less than $50 \mu \mathrm{m}$. Starch acetate, a modified starch, was also used for production of fibers [24]. It was produced by grafting starch with acetic acid or acetic anhydride, wherein catalysts such as perchloric acid or sulfuric acid were used. Fibers spun from a non-thermoplastic starch composition (NTPSC) are summarized as given in Table 2.

Table 2. Fibers spun from non-thermoplastic starch composition (NTPSC) [18].

\begin{tabular}{|c|c|c|}
\hline Title & Process Used & Patent and Year \\
\hline $\begin{array}{l}\text { Water-insensitive starch fibers and a process for } \\
\text { the production thereof }\end{array}$ & $\begin{array}{l}\text { Wet spinning of native and modified starch into an } \\
\text { ammonium sulfate bath }\end{array}$ & $\begin{array}{r}\text { US4139699 } \\
(1979)\end{array}$ \\
\hline Process for spinning starch fibers & $\begin{array}{l}\text { Wet spinning of native starch and ammonium } \\
\text { sulfate aqueous dispersion into ammonium sulfate } \\
\text { bath }\end{array}$ & $\begin{array}{r}\text { US4853168 } \\
(1989)\end{array}$ \\
\hline $\begin{array}{l}\text { Fiber from blend of cellulose acetate and starch } \\
\text { acetate }\end{array}$ & & $\begin{array}{r}\text { US5446140 } \\
(1995)\end{array}$ \\
\hline $\begin{array}{l}\text { Non-thermoplastic starch fibers and starch } \\
\text { composition for making the same }\end{array}$ & & $\begin{array}{r}\text { US6723160 } \\
(2004 a)\end{array}$ \\
\hline $\begin{array}{l}\text { Non-thermoplastic starch fibers and starch } \\
\text { composition for making the same }\end{array}$ & & $\begin{array}{r}\text { US6802895 } \\
(2004 b)\end{array}$ \\
\hline $\begin{array}{l}\text { Process for making non-thermoplastic starch } \\
\text { fibers }\end{array}$ & $\begin{array}{l}\text { Dry spinning of starch aqueous dispersion with } \\
\text { high temperature attenuatingair flow }\end{array}$ & $\begin{array}{r}\text { US6811740 } \\
(2004)\end{array}$ \\
\hline $\begin{array}{l}\text { Non-thermoplastic starch fibers and starch } \\
\text { composition for making the same }\end{array}$ & & $\begin{array}{r}\text { US7025821 } \\
(2006)\end{array}$ \\
\hline
\end{tabular}


Table 2. Cont.

\begin{tabular}{lcr}
\hline \multicolumn{1}{c}{ Title } & Process Used & Patent and Year \\
\hline $\begin{array}{l}\text { Process for making non-thermoplastic starch } \\
\text { fibers }\end{array}$ & $\begin{array}{c}\text { Dry spinning of starch aqueous dispersion with } \\
\text { high temperature attenuating air flow }\end{array}$ & $\begin{array}{r}\text { US7276201 } \\
(2007)\end{array}$ \\
\hline Method for making polymeric structures & $\begin{array}{l}\text { Making fiber products from starch, PVOH, and a } \\
\text { crosslinking agent (imidazolidinone) and further } \\
\text { adding of cellulose fibers }\end{array}$ & $\begin{array}{r}\text { US7744791 } \\
(2010)\end{array}$ \\
\hline Method for forming fibers & Mixing, extrusion, and drawing of fibers from & US7939010 \\
& starch/PVA composition & $(2011)$ \\
\hline
\end{tabular}

\section{Possible Spinning Techniques for Starch Biopolymer}

\subsection{Conventional Fiber Spinning Methods}

The conventional fiber spinning methods are melt spinning, wet spinning, and dry spinning. These methods have been widely used in synthetic fiber manufacturing. Melt spinning is used for thermoplastic polymers that can be melted. In melt spinning, the polymer melt can be extruded through a spinneret containing a number of holes. The elongational laminar melt flow causes molecular orientation in the machine (drawing) direction that can be even enhanced by drawing and crystallization upon cooling. The schematic drawing for melt spinning is shown in Figure 3.

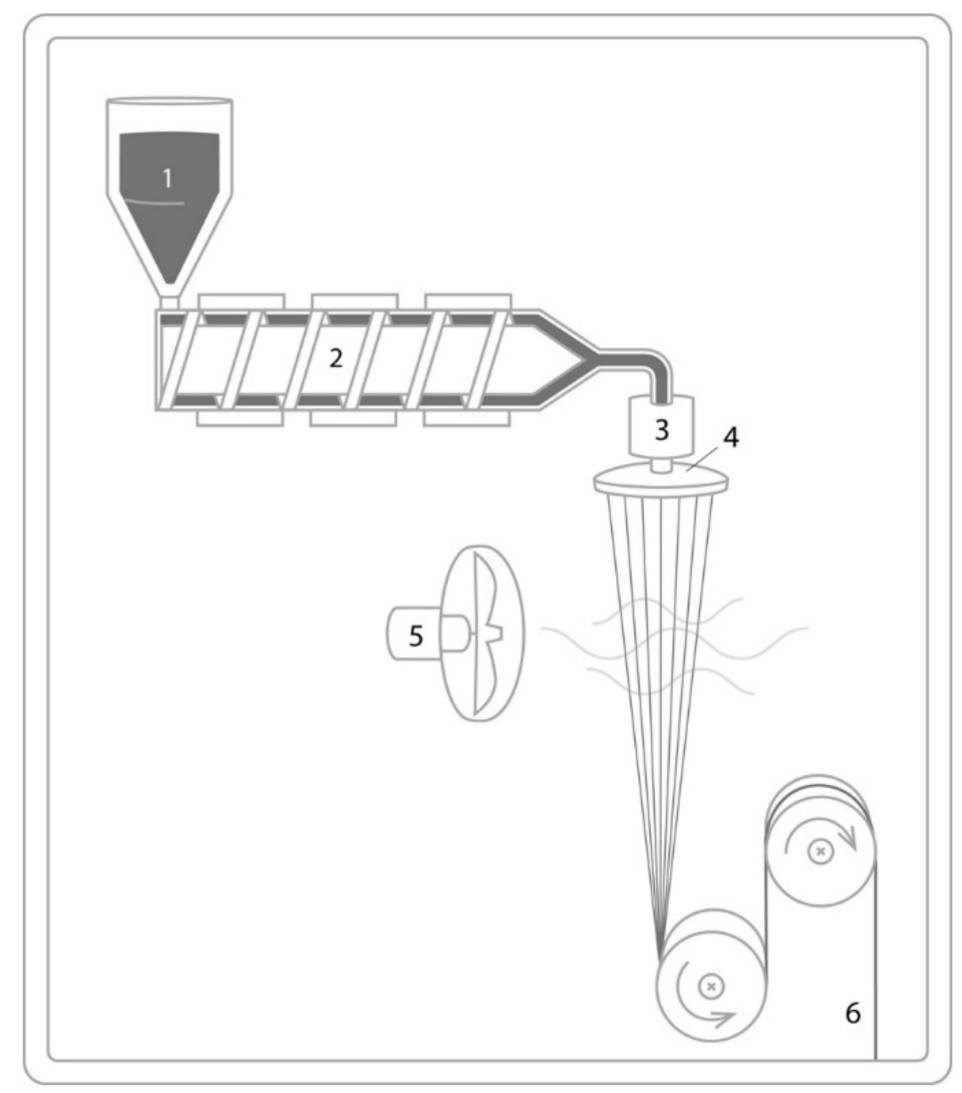

Figure 3. Schematic drawing of melt spinning with a polymer feeder (1), extruder with a single screw (2), the feed pump and nozzle (3), the spinneret (4), cooling air (5) and the winding station (6).

In dry spinning, a solvent is used to dissolve the raw material to form a solution and the fiber is formed from the polymer solution. In this process, the polymer can be dissolved in a volatile solvent, the solution is pumped through the spinneret to form filaments, and air is used to dry the filaments. Usually, the used solvents in dry spinning are expected to have low boiling point and low latent heat or appropriate volatility, respectively. The 
schematic for dry spinning is given in Figure 4a. Wet spinning is the oldest spinning process. In wet spinning, a polymer solution with the desired viscosity will be prepared by dissolving the polymer in a solvent. The formed solution is forced through the submerged spinneret into a coagulation bath containing a non-solvent for the polymer. The solvent in the spinning dope is extracted into the coagulation bath, and the filaments solidify. The schematic for wet spinning is given in Figure $4 b$.
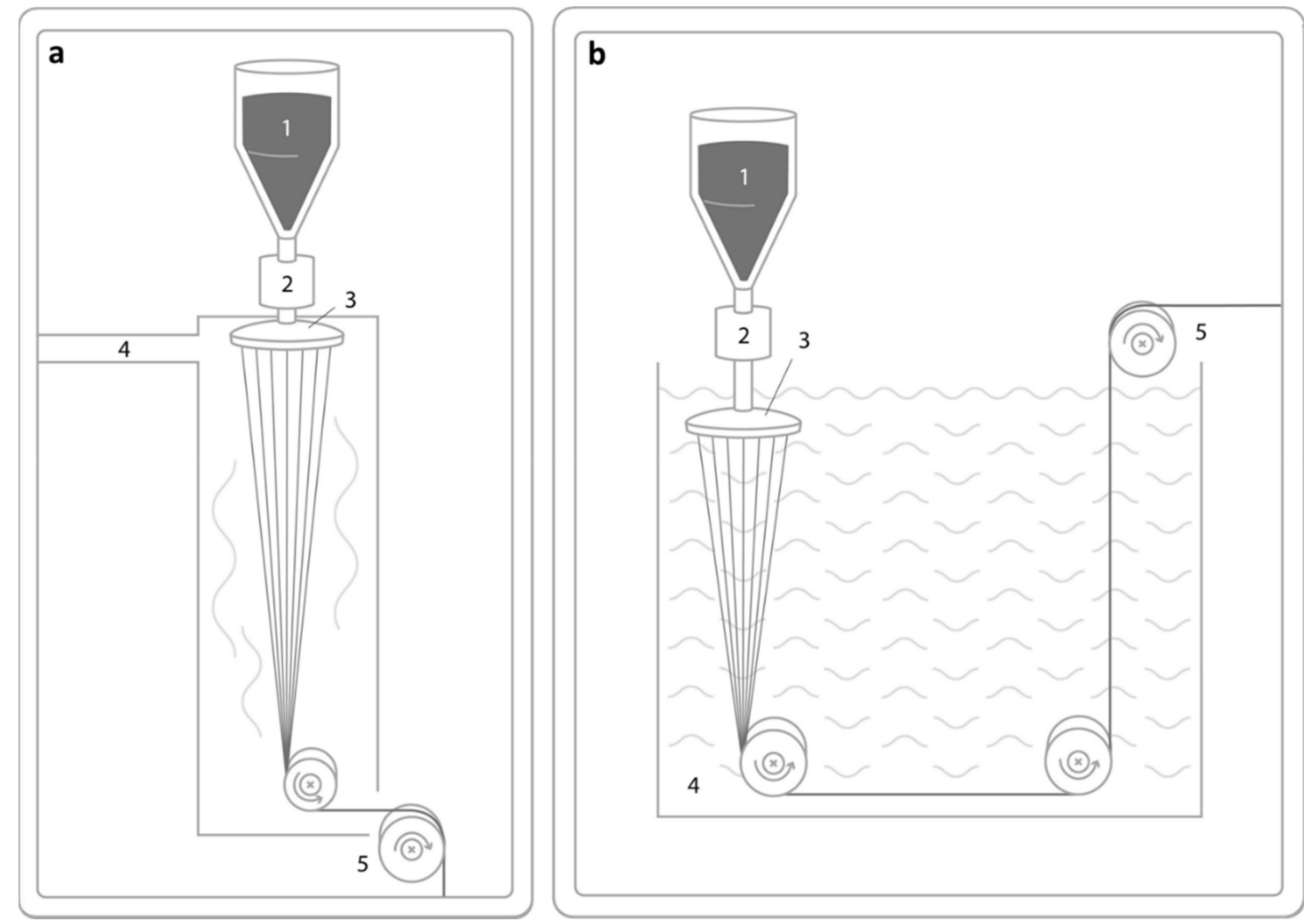

Figure 4. Schematic drawing of dry spinning (a) with the polymer solution (1), the pump (2), spinneret (3,) heated chamber (4), and subsequent winding or further processing (5), and the wet spinning process (b) with the polymer solution (1), pump (2), spinneret (3), coagulation bath (4) and subsequent winding or further processing (5).

These conventional methods have also been widely used in fiber spinning from virgin starch or starch and other polymer blends [28]. Bond et al. [30] described utilization of the melt spinning technique for fiber spinning from starch and polymers blends. In their work, they produced highly attenuated continuous and stable fibers. Another study by the same researches in 2003 revealed the possibility of producing biodegradable fibers from starch and other biodegradable polymers using a melt spinning system [35].

Other researchers have used the wet spinning method for fiber spinning. Nevertheless, the wet-spun fibers are characterized by a coarse diameter, typically greater than $50 \mu \mathrm{m}$, and the large amount of solvent used in this process needs an additional drying step and recovery [36]. Some of the previous studies for wet-spinning starch fibers include U.S. Pat. Nos. 4139699, 4853168 and 4234480 [18]. Some other researchers modified the conventional fiber spinning methods. James et al. [36] developed an air-drawing device to attenuate a non-thermoplastic starch composition extrudate and evaporate the water solvent.

\subsection{Modern Techniques Used for Starch Fiber Spinning}

Besides the conventional spinning methods, different kinds of new spinning techniques have been developed and used for fiber spinning from starch and starch/polymer blends. Some of the novel developments in starch fiber production include electrospinning [19,37-40], electro wet-spinning [41,42], modified electro spinning [43,44] rotary or centrifugal spinning [45-47] and solution blowing [14]. From a feasibility point of view, 
conventional fiber production techniques are still more preferred, because they allow higher outputs and economic benefits [14]. The next section reviews the modern spinning practices which are available for spinning a starch biopolymer and its blend.

\subsubsection{Electrospinning of Fibers from Starch}

Electrospinning is a fiber spinning technique that uses a high voltage electrostatic field for the production of fibers with diameters in the range of micrometer to nanometer scale. It has become a widely used fiber formation technique in the last decade $[14,38]$. The conventional process of fiber spinning is based on the principle of pressure-driven extrusions of a viscous polymer into fibers of diameters ranging from 10 to $500 \mu \mathrm{m}$. Electrospinning as a practical technique for producing nanofibers began in 1934, when Formhals patented his first invention related to the process and apparatus for producing artificial filaments using electric charges [48].

The differences between electrospinning and the conventional methods (wet/dry spinning) are in the fundamentally different processes, where electrostatic attractions enable the process and also the aerodynamic drag at the end of the process [14]. The linearity of amylose and its ability to align and aggregate made the fabrication of amylose fibers preferable in early attempts to fabricate starch fibers [18]. Some researchers patented a process for the fabrication of amylose fibers [43]. Amylose can be preferentially oriented into parallel alignments leading to the formation of hydrogen bonds because of its linear nature, which gives it sufficient freedom of macromolecular chain mobility. In contrast, the branched nature of amylopectin cannot produce this free movement. It cannot align and associate readily. Theoretically, it is known that the amylopectin component of starches can affect fiber spinning and the strength of the fibers spun $[13,18]$.

Approaches for the electrospinning of nanofibers from natural starches will be economically feasible on a commercial scale even if starches with a high amylopectin content are utilized, because amylopectin is the major component in any natural starches. On the other hand, amylopectin as the major constituent of the starch and a highly branched polymer affects the fiber's formation during the electrospinning [40]. Therefore, modification on the electrospinning setup was attempted by many researchers to spin amylopectin-rich starches. This was achieved by Kong et al. by modifying the conventional electro spinning setup [17].

A patent designated by Jennifer et al. [38] described the utilization of an electrospinning technique to produce starch filaments. They described the possibility of producing starch filaments from a mixture of starch, water, plasticizers, and other optional additives such as stabilizers or processing aids. Lancuški et al. [49] produced electrospun fibers from corn starch with a high amylose content using formic acid in different concentrations as a solvent, and subjecting each solution to different aging times, i.e., 2, 6, 24, and $72 \mathrm{~h}$ before electrospinning. The characterization of the fabricated fiber mats signifies that dispersions with formic acid concentrations of 100,90 , and $80 \%$ resulted in fibers with diameters in the range of 80-300 $\mathrm{nm}$.

According to Fonseca et al. [50], soluble potato starch with normal amylose content has been converted into ultrafine fibers by electrospinning like a neat polymer in a fiberforming solution. These researchers prepared fiber-forming polymer solutions with $40 \%$ soluble potato starch (with amylose content of $32.54 \pm 3.65 \%$ ) and formic acid $(75 \%)$ as the solvent. The solutions were allowed to age for $0,24,48$, and $72 \mathrm{~h}$ before electrospinning. The result revealed that ultrafine fibers were successfully electrospun from the solution.

However, in another study, glutinous rice starch and tapioca starch were used for fiber spinning using an electrospinning technique. In this research, water was used as the only solvent and polymeric dispersions were stirred at $80^{\circ} \mathrm{C}$ for $15 \mathrm{~min}$ before electrospinning. From the result, it was revealed that unlike tapioca starch, the glutinous rice starch failed to generate nanofibers during the electrospinning [42,51].

The fabrication of high purity natural tapioca starch (NTS) fibers was reported by Sutjarittangtham et al. [43] using a modified electrospinning technique with a dehydration 
process by using a $-20{ }^{\circ} \mathrm{C}$ ethanol collector bath to complement the conventional electrospinning technique. Electrospun fibers with diameters of $1.3-14.5 \mu \mathrm{m}$ were generated from a simple solution of starch in deionized water with starting concentrations of 3.0 to $5.0 \mathrm{wt} . \%$.

More recently, research conducted by Fonseca et al. [27] revealed the possibility of producing electrospun fibers from native and anionic corn starch with different amylose contents. The electrospun fibers of native and anionic corn starches with regular amylose and high amylose contents were prepared by the electrospinning of starch solutions dissolved in $75 \%$ formic acid solvent. The result revealed that fibers produced from modified anionic starches have homogeneous morphologies, whereas fibers from regular corn starches contained droplets and have heterogeneous morphologies, with diameters varying from 70 to $264 \mathrm{~nm}$. Fibers produced from starches having amylose content less than 70\% have smooth continuous surfaces.

The schematic electrospinning process is given in Figure 5. Studies performed by different researchers on electrospun starch fibers are summarized in Table 3.

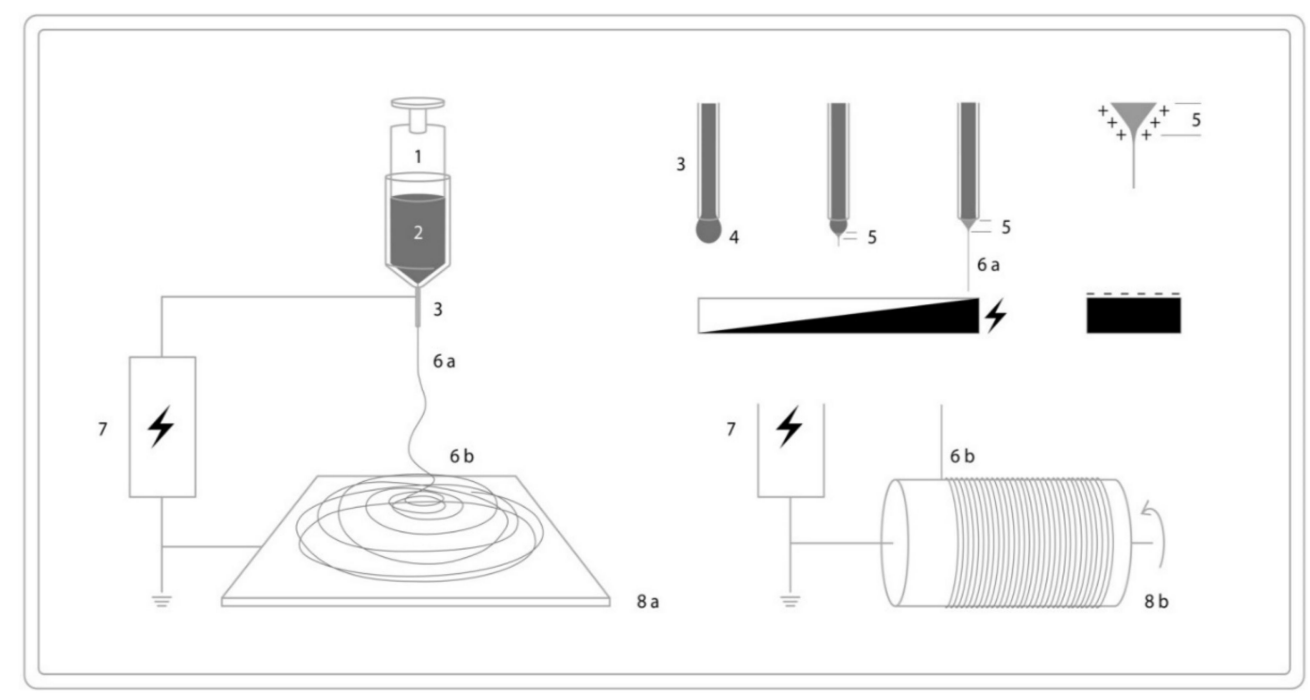

Figure 5. Schematic illustration of electrospinning setup: syringe (pump) (1), polymer solution (2), needle (3), liquid jet (4 and 6a), Taylor cone (5), fibers (6b), circuit (7), collector (8a) and drum collector (8b).

Table 3. Electrospun fibers from starch [50].

\begin{tabular}{lccc}
\hline \multicolumn{1}{c}{ Electrospun Material } & Solvent Used & Characteristics of Obtained Fibers & Year of Publication \\
\hline High amylose pure starch & $\begin{array}{c}\text { Dimethyl sulfoxide } \\
\text { DMSO/water }\end{array}$ & $\begin{array}{c}\text { Fibers with diameter in range of } \\
\text { micrometer }\end{array}$ & 2014 \\
\hline $\begin{array}{l}\text { Pure maize starch with }(70 \%) \\
\text { amylose content }\end{array}$ & $\begin{array}{c}17 \% \text { w aqueous formic acid } \\
\text { solution }\end{array}$ & $\begin{array}{c}\text { Diameter ranging from } \\
80 \text { to 300 nm }\end{array}$ \\
\hline $\begin{array}{l}\text { High amylopectin corn starch } \\
\text { and potato starch }\end{array}$ & $\begin{array}{c}2 \% w / w \text { caustic soda solution } \\
\text { Waxy rice starch }\end{array}$ & Submicron average diameter \\
\hline $\begin{array}{l}\text { High amylose modified starch } \\
70 \% \text { acetic anhydride }\end{array}$ & $\begin{array}{c}\text { Ionic liquid 1-ally-1-3 } \\
\text { methylimidazolium chloride }\end{array}$ & $\begin{array}{c}\text { Multiple flaky layers, highly porous } \\
\text { Diameter from 10 to 100 nm }\end{array}$ \\
\hline $\begin{array}{l}\text { Modified maize starch with } \\
\text { high amylose and }\end{array}$ & Formic acid & $\begin{array}{c}\text { Tensile strength depends on starch to } \\
\text { acetate ratio, annealing time, and } \\
\text { degree of substitution }\end{array}$ \\
\hline
\end{tabular}


Table 3. Cont.

\begin{tabular}{lccc}
\hline \multicolumn{1}{c}{ Electrospun Material } & Solvent Used & Characteristics of Obtained Fibers & Year of Publication \\
\hline $\begin{array}{l}\text { High amylose modified maize } \\
\text { starch 50\% acetic anhydride }\end{array}$ & Dimethyl sulfoxide DMSO & Ultrafine fibers & 2013 \\
\hline $\begin{array}{l}\text { High amylose modified starch } \\
70 \% \text { formic acid solution }\end{array}$ & $\begin{array}{c}17 \% \text { aqueous formic acid } \\
\text { solution }\end{array}$ & $\begin{array}{c}\text { Diameter ranging from } \\
80 \text { to } 300 \mathrm{~nm}\end{array}$ \\
\hline $\begin{array}{l}\text { Acidified oxidized potato } \\
\text { starch }\end{array}$ & DMSO & $\begin{array}{c}\text { Slongation at break higher than } \\
\text { native starch }\end{array}$ & $\begin{array}{c}2015 \\
\text { Natural tapiaco starch }\end{array}$ \\
\hline Native and anionic corn starch & Deionized water & Diameter from 1.3 to $14.5 \mu \mathrm{mm}$ \\
\hline
\end{tabular}

\subsubsection{Electrospun Fibers from Starch/Polymer Blends}

In order to overcome problems associated with natural starches, starches can be blended with other polymers, chemically crosslinked, or plasticized to improve their properties [18,48]. In this case, the addition of a second polymer is intended to promote entanglement. Likewise, the addition of starch can provide the ability to adjust the surface properties of polymer fibers [50]. The common limitations of native starch are related to their poor mechanical property, thermal stability, and their high hygroscopicity. To overcome the limitations and improve their properties, starches are usually blended with other polymers [51]. Starch blending with other polymers is generally intended for the reduction in production cost and improving the properties of starch [49].

Šukyte et al. [52] prepared nanofibers from potato starch, PVA, and small amounts of ethanol. The results showed that with an amount of $5 \mathrm{wt} . \%$ potato starch as a blend partner it was impossible to form nanofibers by the electrospinning process. In this study, it was revealed that even a small amount of ethanol had a significant positive influence on the electrospinning process, although it negatively influenced the nanofibers and the associated web structure. Wang et al. [53] prepared fibers of oxidized starch with PVA of $380 \mathrm{~nm}$ by means of electrospinning, demonstrating that a high concentration of starch in solution notably affects the homogeneity of fibers. According to Jukola et al. [54], there is a possibility of producing electrospun nanofibers using PCL and starch. In this study, a high concentration of starch was used, and the result revealed the formation of highly porous scaffolds. Electrospinning with starch in multicomponent solution was realized by Sunthornvarabhas et al. [55] using a solution of polylactic acid (PLA) with dichloromethane (DCM) and a solution with cassava starch dissolved in dimethyl sulfoxide (DMSO). The result revealed a fiber structure with homogenous diameter.

Bicomponent nanofibers from PVA/cationic starch solution were produced by using electrospinning [56]. In this research, ethanol was used as a solvent. The result revealed the successful formation of nanofibers with different thicknesses, with varying properties dependent on the cationic starch. Some other researchers produced fibers from blends of modified starch and other polymers using electrospinning [57]. Starch nanocellulose composite fibers with increased mechanical strength have been prepared by Wang et al. [58] by using nanocellulose as a reinforcing filler and cationic starch as a binding agent (matrix). Other researchers produced a core-sheath compound with fibers from starch-formate solution using coaxial spinning [59]. The produced fibers had mean diameters of $4.13 \pm 1.05 \mu \mathrm{m}$. Fibers electrospun from blends of starches and other polymers are summarized in Table 4. 
Table 4. Electrospun fibers from starch/polymer blends [14,60].

\begin{tabular}{|c|c|c|c|}
\hline Electrospun Materials & Solvent Used & Characteristics of Fibers Obtained & Year of Publication \\
\hline Starch/PCL 30/70 wt.\% & Acetic acid or chloroform & $\begin{array}{l}\text { Diameter } 130-180 \mathrm{~nm} \\
\text { Highly porous }\end{array}$ & 2005 \\
\hline Starch/PCL 17\% $w / v$ & $\begin{array}{l}\text { Chloroform/dimethyl } \\
\text { formamide (DMF) (7:3) }\end{array}$ & Diameter from $400 \mathrm{~nm}$ to $1.4 \mu \mathrm{m}$ & 2010 \\
\hline Starch/PCL 30/70 wt.\% & Chloroform/DMF (7:3) & $\begin{array}{l}\text { Diameter approximately } 400 \mathrm{~nm} \\
\text { fine morphology }\end{array}$ & 2008 \\
\hline Starch/PCL 30/70 wt.\% & Chloroform $40 \% w / v$ & Fiber diameter around $100 \mu \mathrm{m}$ & 2010 \\
\hline $\begin{array}{l}\text { Potato starch }(5 \mathrm{wt} . \%) / \text { polyvinyl } \\
\text { alcohol/PVA }\end{array}$ & Ethanol 5 wt.\% & & 2010 \\
\hline Soluble starch/PVA $1: 1$ or $1: 3$ & Water & Good morphology & 2014 \\
\hline Oxidized starch (OS)/PVA & Water & $\begin{array}{c}\text { Diameter affected by weight ratio of } \\
\text { PAV/OS }\end{array}$ & 2011 \\
\hline Cationic starch (CS)/PVA (3:1) & Water & & 2012 \\
\hline Cationic starch (CS)/PVA & Ethanol/water & Thicker and stick nanofiber & 2009 \\
\hline $\begin{array}{l}\text { Starch/poly (lactide-co-glycolide) } \\
\text { (PLGA) }\end{array}$ & $\begin{array}{l}\text { Starch in DMSO and PLAGA } \\
\text { in tetrahydrofuran (THF)/N }\end{array}$ & & 2011 \\
\hline Cassava starch/PLA & $\begin{array}{l}\text { PLA in dichloromethane, } \\
\text { cassava starch in DMSO }\end{array}$ & Smooth fibers & 2011 \\
\hline $\begin{array}{l}\text { High amylose maize starch, } \\
\text { cationic starch and Nanocellulose }\end{array}$ & $\begin{array}{l}\text { Dimethyl sulfoxide and } \\
\text { ethanol }\end{array}$ & Good strength & 2018 \\
\hline $\begin{array}{l}\text { Rice starch/PVA } \\
(25 \text { wt. } \%)\end{array}$ & Water and $\mathrm{NaoH}$ & $\begin{array}{l}\text { Uniform fibers with diameter } \\
\text { 36-151 nm }\end{array}$ & 2017 \\
\hline $\begin{array}{l}\text { Glutinous rice starch/PVA }(2 w / v \\
\text { and } 8 w / v)\end{array}$ & Hot water & $\begin{array}{l}\text { Smooth morphology with diameter } \\
191-263 \mathrm{~nm}\end{array}$ & 2017 \\
\hline Starch formate/glycerol (17 wt.\%) & Formic acid & Fibers with diameter $4.13 \mu \mathrm{m}$ & 2017 \\
\hline $\begin{array}{l}\text { Corn starch/guar gum } \\
\text { (3 wt.\%) }\end{array}$ & Water & Fibers with diameter $95 \mathrm{~nm}$ & 2017 \\
\hline Starch acetate (20 wt.\%) & Formic acid/water $(90: 10 v / v)$ & $\begin{array}{l}\text { Fibers with good tenacity and } \\
\text { uniformity }\end{array}$ & 2009 \\
\hline Carboxymethyl starch/PLA & Sodium dodecyl sulfate & Diameter 190-265 nm & 2019 \\
\hline
\end{tabular}

\subsubsection{Electro Wet Spinning}

Kong and Zeigler [17] developed a pure starch microfiber web by modifying the conventional electrospinning technique with a coagulation bath (electro wet spinning). The concept of electro wet spinning is to electrospin pure starch fibers without additional polymers as binders or a matrix. To produce pure starch microfibers, the spinning dope solution was prepared by heating Gelose 80 (amylose content-80\%) in 95\% dimethyl sulfoxide (DMSO) until the gelatinization of starch started. In this process, ethanol was used as a solvent for the coagulation bath because of its miscibility with DMSO and its non-miscibility with starch. The reason for modification of the electrospinning technique with a coagulation bath was to obtain solid fibers with the evaporation of DMSO, which a critical step due to its non-volatility. The addition of pure ethanol in a coagulation bath resulted in the formation of an amorphous electrospun web and the starch web crystallinity was increased to $43 \%$ as the water proportion in the ethanol coagulation bath was increased. This study revealed that the average diameter of electrospun starch fibers was $2.60 \mu \mathrm{m}$. The developed electrospun web was heat-treated to improve the crystallinity (size and degrees of crystals). The stability of the braid against water was improved by crosslinking with glutaraldehyde [52]. 
Cardenas et al. [37] also produced microfibers from potato starch using the electro wet spinning technique. These researchers changed different parameters during their study for each treatment and produced starch microfibers with average diameters of 15, 17, 23 and $25 \mu \mathrm{m}$. These fibers had a degradation temperature of $304{ }^{\circ} \mathrm{C}$, which indicated stable thermal properties even with very thin fiber diameters. Another comparative study by Cardenas et al. [41] revealed the production of wet electrospun fibers with diameters of less than $50 \mu \mathrm{m}$ from local and commercial potato starches using ethanol as a solvent. They also studied the spinnability of cationized and uncationized fibers. They concluded that cationized fibers are less heat resistant and non-cationized fibers have a high amorphous morphology.

\subsubsection{Centrifugal Spinning}

Centrifugal spinning is also known as rotary jet spinning, rotor spinning, and force spinning [61]. Although centrifugal spinning has been widely used in the glass fiber industry for making micrometer-scale glass fibers, the use of centrifugal spinning for producing polymer fibers, especially polymer nanofibers, is relatively new and is an emerging technique $[45,46,61]$. More recently, FibeRio Technology Corporation commercialized largescale centrifugal spinning machines (Cyclone FE 1.1 M/S and Cyclone FS 1.1) for the mass production of polymer nanofibers. In centrifugal spinning, the centrifugal force is utilized to drive polymeric jets out of spinnerets [47]. Compared with electrospinning, it combines the advantages of a high production rate, applicability to a broad range of materials, and insensitivity to dielectric constant of materials. Another advantage is that porous and well-aligned structures are produced. Both centrifugal spinning and electrospinning are effective techniques for the production of micro- and nanofibers. Pure starch-based fibers were successfully fabricated by "electro-wet-spinning" by Kong and Ziegler [17,18]. The techniques used for a successful pure starch-based electro-wet-spinning were demonstrated to be suitable for starches with amylopectin content below $65 \%$ and sensitive to the amylopectin content of starches, and limited the spinnability of amylopectin starches by this process [17].

However, other researchers, Li et al. [61] attempted to produce microfibers by centrifugal spinning technique from various starches such as amylose-rich starch, amylopectin-rich starch, potato starch, and waxy starch. In this study, it was revealed that amylopectin-rich starch-based fibers with an average diameter of sub-microns could be successfully spun from amylopectin-rich native corn and potato starches by centrifugal spinning [46]. The amount of amylopectin of the used native corn and potato starches were determined to be about 68.89 and $73.35 \%$. The produced fibers from amylopectin rich corn starch had a smooth surface, and the fibers obtained from amylopectin-rich potato starch had a rough surface. A method for controlling the surface morphology and topography of centrifugally spun starch-based fibers by adjusting the ratio of amylopectin/amylose in starches and the combination with a hot blast temperature was developed by Li et al. [45]. The effects of hot blast temperature, amylopectin, and amylose on fiber surface morphologies were investigated by using potato and corn starches. The structural analysis of the prepared fibers demonstrated that both corn- and potato-based fibers were amorphous, and some physicochemical changes such as the swelling of granules, loss of order in both amorphous and crystal domains, exudation of amylose, chain rearrangement, and chemical gelatinization occurred during centrifugal spinning. Figure 6 represents the typical schematic process for the representation of centrifugal spinning. 


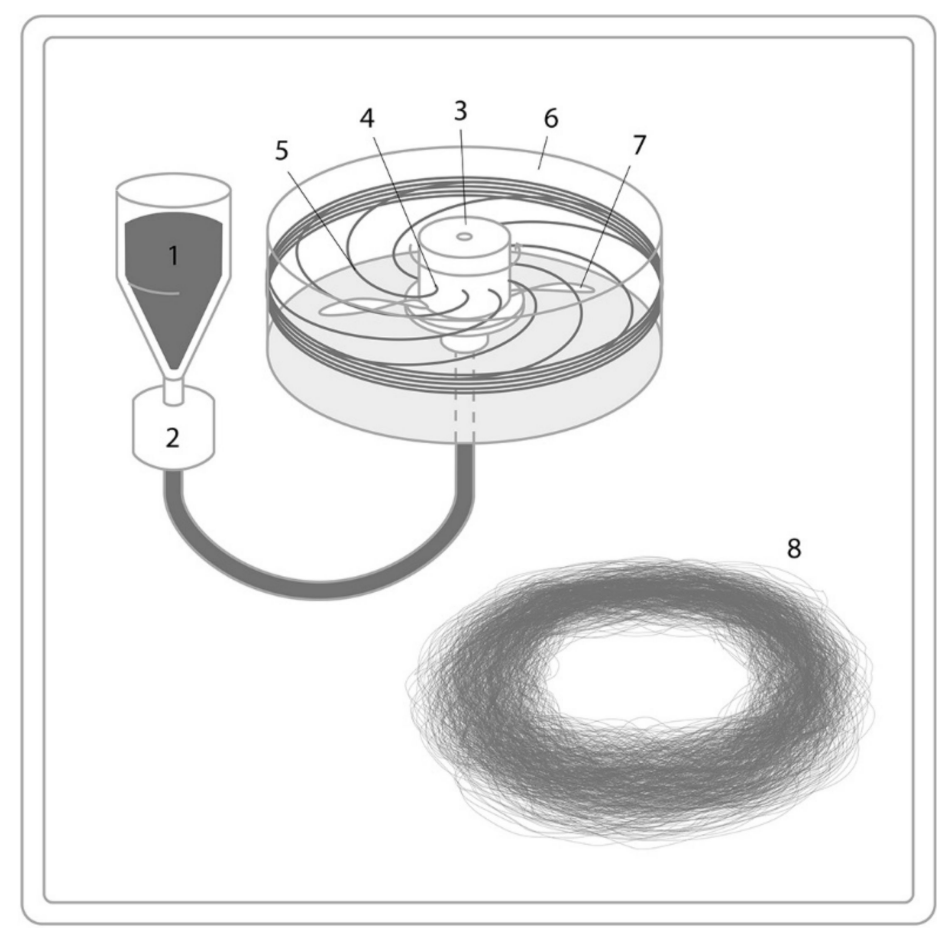

Figure 6. Centrifugal/rotary jet spinning setup with polymer (1), pump (2), polymer path (3), flexible air foil (4), rotating reservoir (6,7), and fibers (8).

\subsubsection{Solution Blow Spinning}

Solution blow spinning (SBS) has been used industrially since the end of the 19th century, and it is one of the oldest methods of synthetic fiber production. Solution blow spinning is obtained by the combination of elements of both electrospinning and traditional melt blowing technologies [62]. Compared with melt blowing technologies, solution blow spinning has a broad spectrum of possible raw materials and availability. Compared to electrospinning, SBS has a high yield, a short preparation time, and a high usage value. Solution blowing was developed as an alternative method for making non-woven webs of micro- and nanofibers with diameters comparable to those made by the electrospinning process with the advantage of a high production rate [3].

This process combines wet spinning and dry spinning. In both methods, the polymer solution is extruded through the spinnerets into fibers. Solvent used in this process is removed and drawing of the fibers will be performed to reduce the fiber diameter with a consequent improvement of the mechanical strength. In the case of dry spun solution blowing, the polymer solution is pushed through a spinneret into a heated column, called the spinning tower. Within the tower, the polymer solidifies through evaporation of the solvent. In the case of wet spun solution blowing, the spinneret is placed in a chemical bath. Inside the bath, the polymer is precipitated by dilution or a chemical reaction to form fibers [63].

Solution blowing is quite an innovative technique and is less researched for the production of biopolymer fibers. In solution blowing, a polymer solution is extruded and non-polymer melts. Solution blowing is associated to melt blowing. The only difference lies in the solvent evaporation in the former, rather than melt cooling jet solidification in the latter. Solution blowing is basically an isothermal method. Unlike melt blowing [64], which produces microfibers, solution blowing results in nanofibers [3]. The biggest advantage of solution blowing, apart from its ability to blend biopolymers, is its scalability. There are several parameters where solution blowing depends on the nozzle dimensions, air pressure, collecting distance and viscoelasticity of the polymer solution [3]. Figure 7 shows the schematics process for solution blowing. 


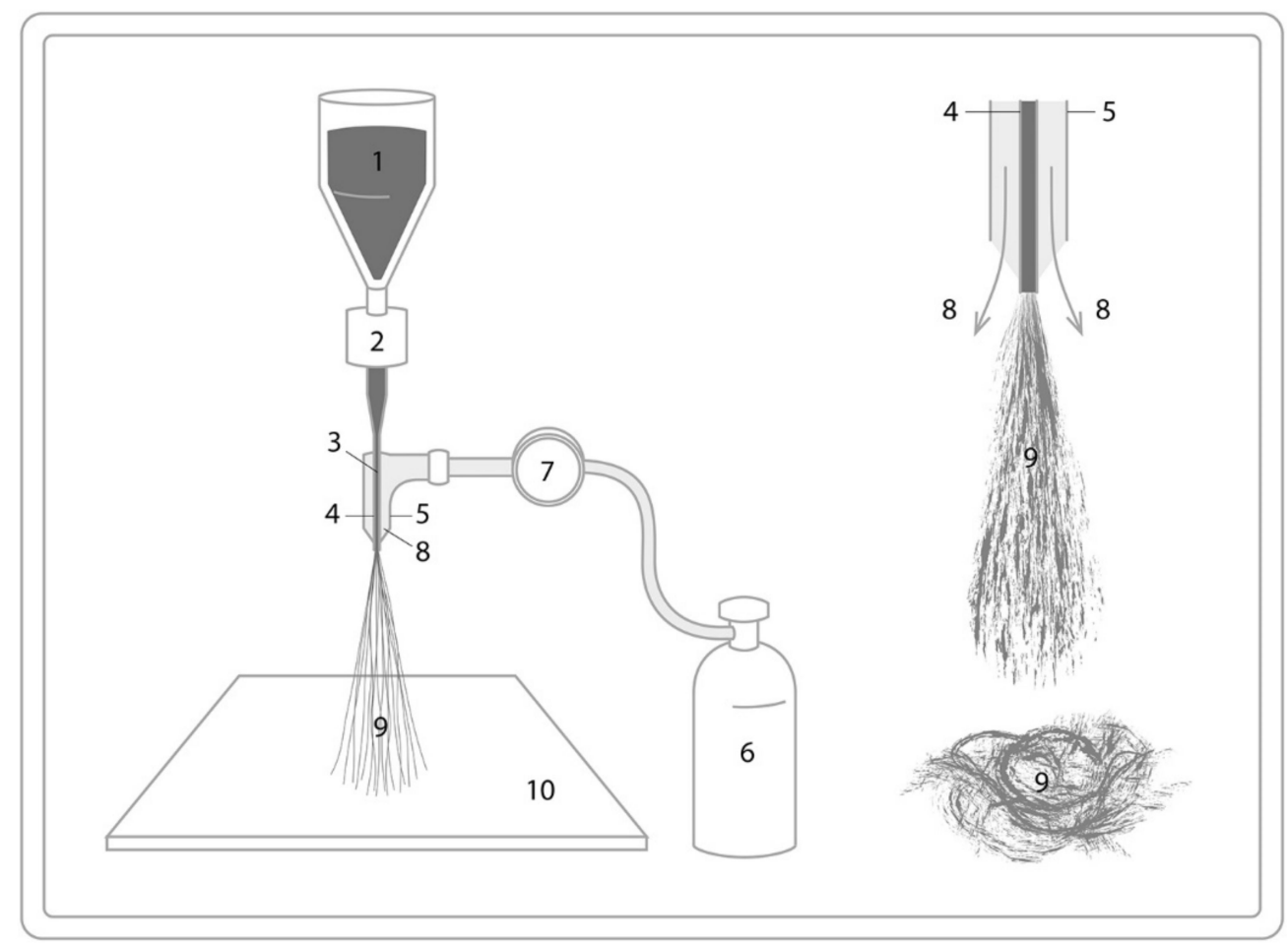

Figure 7. Schematic of the solution blowing process with the polymer (1), coaxial pump (2), syringe (3), polymer solution (4), air supply (5), high pressure air pump (5), valve (7), air (8), stretched polymer jet (9), and the fiber collector (10).

\subsection{Comparison of the Different Fiber Spinning Methods}

All spinning techniques above have advantages and disadvantages and should be chosen depending on the application and the associated property requirements. Table 5 summarizes the advantages and disadvantages of each spinning technique for the production of starch fibers.

Table 5. Comparison of the different fiber spinning technologies [64-67].

\begin{tabular}{|c|c|c|}
\hline Fiber Spinning Methods & Advantages & Disadvantages \\
\hline Melt spinning & $\begin{array}{ll}\text { - } & \text { simple and versatile } \\
\text { process; } \\
\text { as lower manufacturing } \\
\text { cost; } \\
\text { ability to control fiber } \\
\text { diameter; } \\
\text { - } \quad \text { high output compared to } \\
\text { - } \quad \text { nolution spinning; } \\
\text { no solvent needed. }\end{array}$ & $\begin{array}{l}\text { - } \quad \text { risk of thermal degradation } \\
\text { due to high shear rates; } \\
\text { variable diameters } \\
\text { distribution; } \\
\text { - } \quad \text { high energy consumption; } \\
\text { - limited to large fiber } \\
\text { diameter. }\end{array}$ \\
\hline $\begin{array}{l}\text { Solution Spinning } \\
\text { (dry and wet) }\end{array}$ & $\begin{array}{ll}\text { - } & \text { low energy } \\
\text { consumption; } \\
\text { - } \quad \text { variety of structures; } \\
\text { pre-controlled fiber } \\
\text { diameter. }\end{array}$ & $\begin{array}{l}\text { - } \quad \text { removal of solvent required; } \\
\text { - } \quad \text { difficult to obtain aligned } \\
\text { fibers; } \\
\text { - } \\
\text { environmental impact of } \\
\text { solvents. }\end{array}$ \\
\hline
\end{tabular}


Table 5. Cont.

\begin{tabular}{|c|c|c|}
\hline Fiber Spinning Methods & Advantages & Disadvantages \\
\hline Melt electro-spinning & $\begin{array}{l}\text { - } \quad \text { solvent free process; } \\
\text { - } \quad \text { low process costs; } \\
\text { long and continuous } \\
\text { fibers. }\end{array}$ & $\begin{array}{l}\text { - } \quad \text { low outputs; } \\
\text { - } \quad \text { limited varieties of polymer; } \\
\text { - } \quad \text { risk of blocking the needle; } \\
\text { - } \quad \text { risk of thermal degradation; } \\
\text { - } \quad \text { electric discharge problems. }\end{array}$ \\
\hline Solution electrospinning & $\begin{array}{l}\text { - } \quad \text { used for long and } \\
\text { continuous fibers; } \\
\text { - } \quad \text { easy to set up; } \\
\text { - } \quad \text { diviform in diameter; } \\
\text { compositiod in }\end{array}$ & $\begin{array}{ll}\text { - } & \text { requires solvent recovery; } \\
\text { - } & \text { risk of toxic contamination; } \\
\text { - } & \text { jet instability; } \\
\text { - } & \text { low output for single } \\
& \text { spinneret. }\end{array}$ \\
\hline Centrifugal spinning & $\begin{array}{ll}\text { - } & \text { simple, safe, and } \\
\text { eco-friendly process; } \\
\text { - free from high electric } \\
\text { field and solvents; } \\
\text { - } \quad \text { high production rates; } \\
\text { - low costs. }\end{array}$ & $\begin{array}{l}\text { might require high } \\
\text { temperature. }\end{array}$ \\
\hline Solution blow spinning & $\begin{array}{l}\text { - large-scale fabrication; } \\
\text { - } \quad \text { wide range of materials; } \\
\text { good industrialization } \\
\text { prospect. }\end{array}$ & $\begin{array}{l}\text { - } \quad \text { random deposition; } \\
\text { poor fiber morphology. }\end{array}$ \\
\hline Template synthesis & $\begin{array}{l}\text { - } \quad \text { simple and one step } \\
\text { process; } \\
\text { - } \quad \text { suitable for longer fibers; } \\
\text { easy to change diameter } \\
\text { by using different } \\
\text { templates. }\end{array}$ & $\begin{array}{l}\text { - } \quad \text { lower productivity; } \\
\text { non-uniform fiber } \\
\text { size/shape; } \\
\text { - complex process. }\end{array}$ \\
\hline Self-assembly & $\begin{array}{l}\text { - easy to obtain smaller } \\
\text { nanofibers. }\end{array}$ & - complex process. \\
\hline Melt blowing & $\begin{array}{l}\text { - long and continuous } \\
\text { fibers; } \\
\text { - } \quad \text { high productivity; } \\
\text { no need of solvent } \\
\text { recovery. }\end{array}$ & $\begin{array}{l}\text { - } \quad \text { polymer limitations; } \\
\text { - } \quad \text { risk of thermal degradation; } \\
\text { - } \quad \text { expensive process; } \\
\text { - } \quad \text { complex setup needed }\end{array}$ \\
\hline Phase separation & 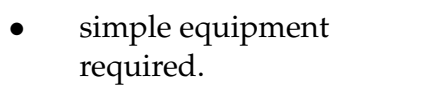 & $\begin{array}{l}\text { only works with selective } \\
\text { polymers. }\end{array}$ \\
\hline
\end{tabular}

\section{Application of Bio-Based Materials}

Synthetic polymers are mainly obtained from fossil raw materials (crude oil and fracking gas) as by-products from cracking processes (e.g., naphtha). Fossil resources were created from plant biomass over millions of years. They are therefore not a renewable, but finite resource and need to be substitute by renewable $\left(10^{-1}-1\right.$ years) bio-based resources. For the production of bio-based polymers, different renewable biogenic raw materials 
such as sugars and polysaccharides (especially cellulose), proteins and vegetable oils, as well as biogenic by-products from forest and food industries such as lignin and pine resin derivatives have been used so far [65]. By depolymerization to their monomers by biorefineries with subsequent repolymerization, biopolymers with the identical constitution and properties of synthetic polymers, i.e., drop-in biopolymers such as bio-polyethylene (bio-PE), bio-polyamide (bio-PA), etc., can be created. These polymers can be a one-by-one replacement of fossil-based polymer products, but still cannot solve problems such as the creation of non-biodegradable macro- and microplastics. Alternatively, completely new biopolymers with unique structure-properties relationships have been found and created. One of the most promising alternatives to substitute polyethylene terephthalate (PET) as a transparent plastic bottle packaging application is polyethylene furanoate (PEF), generated from cellulose [68]. These two types of biopolymers are non-biodegradable. Biodegradable plastics made from fossil resources are also considered as biopolymers, e.g., polybutylene adipate terephthalate (PBAT). Sustainability, i.e., using local bio-based resources or carbon capture and biodegradability, have become the most important factors, helping to identify biopolymers from fossil fuel-based polymers. Biodegradable biopolymers can be synthesized from renewable resources, can be used to replace fossil fuel-based-polymers, and are highly demanded where plastic pollution occurs [69-72]. When compared to fossil fuel-based compounds, the use of natural starting materials for the preparation of bio-based products may result in materials with similar or even improved properties [73].

Bio-based and biodegradable polymers have an extensive range of applications such as pharmaceutical, biomedical, horticulture, agriculture, consumer electronics, automotive, textiles, and packaging. The last application is still the most commonly used application in the polymeric industry, with the highest demand for sustainable solutions [5].

The properties and commercial importance of biopolymers can be improved by blending with (i) other biopolymers, (ii) organic or inorganic functional stabilizers, (iii) fillers or (iv) fibers. The resulting biopolymer blends are called biopolymer composites. These composites have a diverse range of applications in the medicine, electronics, construction, packaging, and automotive sectors [74]. The incorporation of bio-based reinforcement materials into biopolymers greatly improves the mechanical properties such as tensile and impact strengths of resulting composites or stabilizes the composite against premature aging [75-77]. These biodegradable polymer composites receive enhanced applications due to their excellent mechanical properties and very good compatibility as well as biodegradability. The most widely used biopolymers for the current development of biopolymer composites are poly(lactic acid) (PLA), cellulose esters, polyhydroxyalkanoates (PHAs), and starch-based plastics [68], as well as polyurethanes [70]. It can be shown that biogenic by-products as additives for bio-composites can improve the properties of the biopolymers. For example, lignin can improve flame retardancy and UV stability [70].

Many bio-based materials have been utilized in the packaging industry. Among the total plastics usage, "packaging" occupies the top position with $41 \%$ of all plastic applications $[69,78]$. Plastic is most often the material of choice for the packaging of food, cosmetics, or pharmaceutical products because of its low cost, light weight, and the excellent protection provided to the packaged product. Even biopolymers are still a niche, although the demand for bio-based materials for packaging is expected to grow to 9.45 million tons by 2023 [71]. Some of the biopolymers used in packaging industry are poly(lactic acid) (PLA) [72], cellulose acetate and cellulose derivates [79], polyhydroxyalkanoate (PHA) [80], proteins [81,82], polybutylene succinate (PBS) [83,84], lipids, and waxes [85] and starch [86,87] Besides packaging application, bioplastics and bio-composites can be used in building and construction materials, and the biomedical, automotive, and textile industries [70]. Along with packaging, plastic textile applications have become more interesting. 


\section{Application of Starch Biopolymers}

Among the natural bio-based polymeric materials, starch has been identified as one of least expensive polysaccharides, which is easily processable with conventional plastic processing equipment. Native starch resources are available all over the world and has a huge potential for solid plastics and other functional polymer applications [71,88]. It is considered as one of the most promising natural polymers because of its inherent biodegradability, overwhelming abundance, and annual renewability [5]. Therefore, the development and applications of biodegradable starch-based materials and composites has become more demanding [89].

Starch is commonly used in food and agriculture industries. It can also be used for other applications such as in adhesives and paper binders, textiles, chemical production, or as a feedstock for fermentation [86]. Starch-based biopolymer composites and fibers have been investigated in different areas of applications [53,89-94]. The interest to use starch biopolymers in advanced materials applications is accrued from its low cost and abundance. Starch as a macromolecule is also appealing because of its physical, chemical and functional properties such as ease of water dissolution, water retention properties, gelatinization, pasting behavior when subjected to elevated temperatures, and ease of modification to optimize functional properties [76].

Some of the advanced application areas of starches are: porous foam structures [95-98], wastewater treatment [99,100], filtration [101], tissue engineering [102,103], drug delivery [104-110], pharmaceutical industry [111,112], antimicrobial films and coatings [113-116], self-healing polymeric materials [117], electronics [118,119] photonics [120], superhydrophobic surfaces [121], sensors [122-125] and as an antioxidant additive [126].

\section{Conclusions and Future Prospects}

The properties of natural polymers such as desirable biocompatibility, biodegradability, chemical stability, non-toxicity, balanced mechanical properties, and high porosity have provided unique advantages compared to synthetic polymers. Starch biopolymer, being the second most abundant biopolymer on earth, should be regarded as a valuable resource for fiber manufacturing. Many research attempts have been made to fabricate fibers from starch and starch/polymer blends. Moreover, the inefficient mechanical strength, hydrophilicity, decreased thermal stability, and difficulty in processability still limit the application of starches for industrial uses, and particularly their application for fiber fabrication. To overcome these limitations, various processes including plasticization and physical, chemical, enzymatic, and genetic modifications have been studied. Blending starch with other biopolymers is outlined as a viable alternative to overcome these limitations and can particularly enhance the mechanical and thermal properties of native starch. Besides the blending and modification of starches, new techniques for spinning starch to micro- and nanofibers have also been developed for their application in different fields.

Spinning starch has been performed with additives such as processing aids and without additives. The spinning of native starch has been proved successful for the first time by using electro-spinning. Extensive works are being conducted to fabricate starch fibers from native, modified, and thermoplastic starches using different spinning methods. A number of reviews reported on starch fiber spinning, although most of them cover only a few spinning methods comparatively. This review discussed the recent progress in spinning starch fibers and summarized technologies used in fiber spinning along with their comparison. The review also discussed the progress in applications of starch biopolymers and fibers in areas of different technological applications.

Even though there are attempts made in the fabrication of starch fibers from native starches, extensive research and development works are required to develop appropriate and more efficient spinning technologies for starch biopolymers in order to fully utilize them as a source for a bio-based high-value product. Melt spinning has the potential for continuous fiber extrusion with high outputs. In order to minimize shear fracture and the associated degradation of the starch and breaks of the fibers, future work should focus 
on starch compounds with alternative, eco-friendly plasticizers. Natural plasticizers are supposed to influence the physical structure of starch-based polymers and the rheological properties. The investigation of several processing parameters such as the drawing ratio and cooling conditions might have a decisive influence on the microstructure, and thus the final fiber properties. The characterization of the processing-structure-property relationships of starch-based fibers is part of the future investigations, and will contribute to life cycle assessments and global bioeconomic strategies.

Author Contributions: The paper was designed and conceived by all the authors. S.T., conceptualization and writing — original draft preparation. M.R., conceptualization and writing-review and editing, visualization. T.T., writing-review and editing. M.N., editing and supervision. All authors have read and agreed to the published version of the manuscript.

Funding: This research received no external funding.

Institutional Review Board Statement: Not applicable.

Informed Consent Statement: Not applicable.

Data Availability Statement: The data presented in this study are available in the below listed references.

Acknowledgments: The authors would like to acknowledge the financial support from the Institute for Biopolymers and Sustainability, (ibp) at Hof University of Applied Sciences to cover the article processing charge (APC). In addition, we would like to thank Ulrike Mutschke from the ibp for her graphical support in preparation of the manuscript.

Conflicts of Interest: The authors declare that there is no conflict of interest.

\section{References}

1. Trade and Development Report 2019: Financing a Global Green New Deal; United Nations Conference on Trade and Development: Geneva, Switzerland, 2019.

2. Sadasivuni, K.K.; Saha, P.; Adhikari, J.; Deshmukh, K.; Ahamed, M.B.; Cabibihan, J.J. Recent advances in mechanical properties of biopolymer composites: A review. Polym. Compos. 2020, 41, 32-59. [CrossRef]

3. Kumar, A.; Sinha-Ray, S. A review on biopolymer-based fibers via electrospinning and solution blowing and their applications. Fibers 2018, 6, 45. [CrossRef]

4. Hemamalini, T.; Giri Dev, V.R. Comprehensive review on electrospinning of starch polymer for biomedical applications. Int. J. Biol. Macromol. 2018, 106, 712-718. [CrossRef] [PubMed]

5. Belén, M.; Encalada, K.; Proaño, E. An overview of starch-based biopolymers and their biodegradability Una revisión sobre biopolímeros con base en almidón y su biodegradabilidad. Cienc. E Ing. 2018, 39, 245-258.

6. Fink, J.K. Carbohydrate Related Polymers. Chem. Bio-Based Polym. 2014, 137-170. [CrossRef]

7. Kaseem, M.; Hamad, K.; Deri, F. Thermoplastic starch blends: A review of recent works. Polym. Sci. Ser. A 2012, 54, 165-176. [CrossRef]

8. Babu, R.P.; Connor, K.O.; Seeram, R. Current progress on bio-based polymers and their future trends. Progress Biomater. 2013, 2, 1-16. [CrossRef]

9. Azwar, E.; Hakkarainen, M. Tuning the Mechanical Properties of Tapioca Starch by Plasticizers, Inorganic Fillers and AgrowasteBased Fillers. Int. Sch. Res. Not. 2012, 201. [CrossRef]

10. Article, R.; Neelam, K.; Vijay, S.; Lalit, S. Various Techniques for modification of starch and the application of its derivatives. Int. Res. J. Pharm. 2012, 3, 25-31.

11. Marjadi, D.; Dharaiya, N.A. Bioplastic: A better alternative for sustainable future. Everyman Sci. 2010, 15, 90-92.

12. Fitzgerald, A.; Proud, W.; Kandemir, A.; Murphy, R.J.; Jesson, D.A.; Trask, R.S.; Hamerton, I.; Longana, M.L. A Life Cycle Engineering Perspective on Biocomposites as a Solution for a Sustainable Recovery. Sustainability 2021, 13, 1160. [CrossRef]

13. Kong, L.; Ziegler, G.R.; Bhosale, R. Fibers spun from polysaccharides. In Handbook of Carbohydrate Polymers: Development, Properties and Applications; Nova Science Publishers, Inc.: Hauppauge, NY, USA, 2011; pp. 1-43. ISBN 9781608763672.

14. Ashraf, R.; Sofi, H.S.; Malik, A.; Beigh, M.A.; Hamid, R.; Sheikh, F.A. Recent Trends in the Fabrication of Starch Nanofibers: Electrospinning and Non-electrospinning Routes and Their Applications in Biotechnology. Appl. Biochem. Biotechnol. 2019, 187, 47-74. [CrossRef]

15. Antonio, J.F. Starch: Major Sources, Properties and Applications as Thermoplastic Materials. In Monomers, Polymers and Composites from Renewable Resources; Belgacem, M.N., Gandini, A., Eds.; Elsevier Ltd.: Amsterdam, The Netherlands, 2008. [CrossRef]

16. Curvelo, A.A.S.; De Carvalho, A.J.F.; Agnelli, J.A.M. Thermoplastic starch-cellulosic fibers composites: Preliminary results. Carbohydr. Polym. 2001, 45, 183-188. [CrossRef] 
17. Kong, L.; Ziegler, G.R. Fabrication of pure starch fibers by electrospinning. Food Hydrocoll. 2014, 36, 20-25. [CrossRef]

18. Kong, L.; Ziegler, G.R. Patents on Fiber Spinning from Starches. Recent Pat. Food Nutr. Agric. 2012, 4, 210-219. [CrossRef] [PubMed]

19. Zussman, E.; Lancuski, A. High-amylose starch- formate electrospun fibers. WO 2016/132370, 25 August 2016.

20. Bailey, V.A.; Mackey, L.N.; Trokhan, P.D. Starch fiber. US7704328B2, 27 April 2010.

21. Maddah, H.A. Polypropylene as a Promising Plastic: A Review. Am. J. Polym. Sci. 2016, 6, 1-11. [CrossRef]

22. Chadehumbe, C. Tensile Properties of Thermoplastic Starch and Its Blends With Polyvinyl Butyral and Polyamides. Ph.D. Thesis, University of Pretoria, Pretoria, South Africa, August 2006.

23. Bailey, V.A.; Mackey, L.N.; Trokhan, P.D. Melt processable starch compositions. US7666261B2, 23 February 2010.

24. Huneault, M.; Li, H. Process of Producing Thermoplastic Starch/Polymer Blends. US9045625B2, 2 June 2015.

25. Guzmán, M.; Murillo, E.A. Structural, thermal, rheological, morphological and mechanical properties of thermoplastic starch obtained by using hyperbranched polyester polyol as plasticizing agent. DYNA 2018, 85, 178-186. [CrossRef]

26. Tanaka, H.; Miyahara, Y.; Kasetani, S.; Esaki, K.; Nishimura, S.; Inoue, T. Biodegradable nonwoven fabrics and method of manufacturing same. US5614298A, 25 March 1997.

27. Fonseca, L.M.; de Oliveira, J.P.; de Oliveira, P.D.; da Rosa Zavareze, E.; Dias, A.R.G.; Lim, L.T. Electrospinning of native and anionic corn starch fibers with different amylose contents. Food Res. Int. 2019, 116, 1318-1326. [CrossRef] [PubMed]

28. Tuzlakoglu, K.; Pashkuleva, I.; Rodrigues, M.T.; Gomes, M.E. A new route to produce starch-based fiber mesh scaffolds by wet spinning and subsequent surface modification as a way to improve cell attachment and proliferation. J. Biomed. Mater. Res. A 2009, 92, 369-377. [CrossRef]

29. Bond, E.B.; Wheeler, D.S.; Arora, K.A. High elongation splittable multicomponent fibers comprising starch and polymers. US6743506B2, 1 June 2004.

30. Bond, E.B.; Autran, J.-P.M.; Mackey, L.N.; Noda, I.; O’Donnell, H.J. Fibers comprising starch and biodegradable polymers. US6946506B2, 20 September 2005.

31. Lorcks, J.; Pommeranz, W.; Schmidt, H. Biodegradable fibers manufactured from thermoplastic starch and textile products and other articles manufactured from such fibers. US6218321B1, 17 April 2001.

32. Nakajima, Y.; Taniguchi, M. Biodegradable fiber and non-woven fabric. US6045908A, 4 April 2000.

33. Eden, J.; Trksak, M. Process for spinning starch fibers. US4853168A, 1 August 1989.

34. James, M.D.; Mackey, L.N.; Ensign, D.E.; Aydore, S. Process for making non-thermoplastic starch fibers. US6811740B2, 2 November 2004.

35. James, M.D.; Mackey, L.N.; Ensign, D.E.; Aydore, S. Process for making non-thermoplastic starch fibers. US7276201B2, 2 October 2007.

36. Bastioli, C.; Casale, B.; Zanardi, G. Device and process for the production of fibrous starch materials. WO1994009190, 28 April 1994.

37. William, A.C.; Efrén, M.P.; Yesid, G.P.E.; Ricardo, V.G. Comparative Study of Starch Fibers Obtained by Electro-spinning of Indigenous, Commercial and Cationic Potato Starch. J. Nat. Fibers 2020, 17, 809-819. [CrossRef]

38. Ebner von Eschenbach, J. Electro-spinning process for making starch filaments for flexible structure. EP1217107A1, 26 June 2002.

39. Nayak, R.; Padhye, R. Nano Fibres by Electro spinning: Properties and Applications. J. Text. Eng. Fash. Technol. 2017, 2, 486-497. [CrossRef]

40. Kong, L.; Ziegler, G.R. Formation of starch-guest inclusion complexes in electrospun starch fibers. Food Hydrocoll. 2014, 38, 211-219. [CrossRef]

41. Cárdenas, W.; Gómez-Pachon, E.Y.; Muñoz, E.; Vera-Graziano, R. Preparation of potato starch microfibers obtained by electro wet spinning. In IOP Conference Series: Materials Science and Engineering; IOP Publishing: Bristol, UK, 2016; Volume 138. [CrossRef]

42. Jaiturong, P.; Sutjarittangtham, K.; Eitsayeam, S.; Sirithunyalug, J. Preparation of glutinous rice starch nanofibers by electrospinning. Adv. Mater. Res. 2012, 506, 230-233. [CrossRef]

43. Jaiturong, P.; Intatha, U.; Eitssayeam, S.; Sirithunyalug, J. Fabrication of Natural Tapioca Starch Fibers by a Modified Electrospinning Technique. Chiang Mai J. Sci. 2014, 41, 213-223.

44. Komur, B.; Bayrak, F.; Ekren, N.; Eroglu, M.S.; Oktar, F.N.; Sinirlioglu, Z.A.; Yucel, S.; Guler, O.; Gunduz, O. Starch/PCL composite nanofibers by co-axial electrospinning technique for biomedical applications. Biomed. Eng. Online 2017, 16, 1-13. [CrossRef]

45. Li, X.; Chen, H.; Yang, B. Centrifugally spun starch-based fibers from amylopectin rich starches. Carbohydr. Polym. 2016, 137, 459-465. [CrossRef]

46. Zhang, X.; Lu, Y. Centrifugal Spinning: An Alternative Approach to Fabricate Nanofibers at High Speed and Low Cost. Polym. Rev. 2014, 54, 677-701. [CrossRef]

47. Rogalski, J.J.; Bastiaansen, C.W.M.; Peijs, T.; Rogalski, J.J.; Bastiaansen, C.W.M.; Peijs, T. Rotary jet spinning review-A potential high yield future for polymer nanofibers. Nanocomposites 2017, 3, 97-121. [CrossRef]

48. Vadas, D.; Kmetykó, D.; Marosi, G.; Bocz, K. Application of melt-blown Poly(lactic acid) fibres in self-reinforced composites. Polymer (Basel) 2018, 10, 766. [CrossRef] [PubMed]

49. Lancuški, A.; Vasilyev, G.; Putaux, J.L.; Zussman, E. Rheological Properties and Electrospinnability of High-Amylose Starch in Formic Acid. Biomacromolecules 2015, 16, 2529-2536. [CrossRef] 
50. Fonseca, L.M.; da Silva, F.T.; Antunes, M.D.; Mello el Halal, S.L.; Lim, L.T.; Dias, A.R.G. Aging Time of Soluble Potato Starch Solutions for Ultrafine Fibers Formation by Electrospinning. Starch Staerke 2019, 71, 1-23. [CrossRef]

51. Liu, G.; Gu, Z.; Hong, Y.; Cheng, L.; Li, C. Electrospun starch nanofibers: Recent advances, challenges, and strategies for potential pharmaceutical applications. J. Control. Release 2017, 252, 95-107. [CrossRef]

52. Šukyte, J.; Adomavičiute, E.; Milašius, R. Investigation of the possibility of forming nanofibres with potato starch. Fibres Text. East. Eur. 2010, 82, 24-27.

53. Wang, H.; Wang, W.; Jiang, S.; Jiang, S.; Zhai, L.; Jiang, Q. Poly(vinyl alcohol)/oxidized starch fibres via electrospinning technique: Fabrication and characterization. Iran. Polym. J. Engl. Ed. 2011, 20, 551-558.

54. Jukola, H.; Nikkola, L.; Ashammakhi, N. Electrospun Starch-Polycaprolactone Nanofiber-Based Constructs for Tissue Engineering. AIP Conf. Proc. 2008, 973, 971-975. [CrossRef]

55. Sunthornvarabhas, J.; Chatakanonda, P.; Piyachomkwan, K.; Sriroth, K. Electrospun polylactic acid and cassava starch fiber by conjugated solvent technique. Mater. Lett. 2011, 65, 985-987. [CrossRef]

56. Adomavičiute, E.; Milašius, R.; Žemaitaitis, A.; Bendoraitiene, J.; Leskovšek, M.; Demšar, A. Methods of forming nanofibres from bicomponent PVA/Cationic starch solution. Fibres Text. East. Eur. 2009, 74, 29-33.

57. Šateike, J.; Milašius, R. Influence of Modified Cationic Starch in a Mixed Poly(Vinyl Alcohol)/Cationic Starch Solution on the Electrospinning Process and Web Structure. Autex Res. J. 2020, 20, 69-72. [CrossRef]

58. Wang, H.; Kong, L.; Ziegler, G.R. Fabrication of starch-Nanocellulose composite fibers by electrospinning. Food Hydrocoll. 2019, 90, 90-98. [CrossRef]

59. Lancu` , A.; Ammar, A.A.; Avrahami, R.; Vilensky, R.; Vasilyev, G. Design of Starch-Formate Compound Fibers as Encapsulation Platform for Biotherapeutics Design of starch-formate compound fibers as encapsulation platform for biotherapeutics. Carbohydr. Polym. 2016, 158, 68-76. [CrossRef]

60. Garalde, R.A.; Thipmanee, R.; Jariyasakoolroj, P.; Sane, A. The effects of blend ratio and storage time on thermoplastic starch/poly (butylene adipate-co-terephthalate ) films. Heliyon 2019, 5, e01251. [CrossRef] [PubMed]

61. Li, X.; Hou, T.; Lu, Y.; Yang, B. A method for controlling the surface morphology of centrifugally spun starch-based fibers. J. Appl. Polym. Sci. 2018, 135, 45810. [CrossRef]

62. Zaaba, N.F.; Ismail, H. A review on tensile and morphological properties of poly (lactic acid) (PLA)/ thermoplastic starch (TPS) blends. Polym. Technol. Mater. 2019, 58, 1945-1964. [CrossRef]

63. Medeiros, E.S.; Glenn, G.M.; Klamczynski, A.P.; Orts, W.J.; Mattoso, L.H.C. Solution Blow Spinning: A New Method to Produce Micro- and Nanofibers from Solution Blow Spinningg: A New Method to Produce Micro- and Nanofibers from Polymer Solutions. J. Appl. Polym. Sci. 2009, 113, 2322-2330. [CrossRef]

64. Hassan, M.A.; Yeom, B.Y.; Wilkie, A.; Pourdeyhimi, B.; Khan, S.A. Fabrication of nanofiber meltblown membranes and their filtration properties. J. Memb. Sci. 2013, 427, 336-344. [CrossRef]

65. Garrison, T.F.; Murawski, A.; Quirino, R.L. Bio-Based Polymers with Potential for Biodegradability. Polymers 2016, 8, 262. [CrossRef]

66. Mohan, S.; Oluwafemi, O.S.; Kalarikkal, N.; Thomas, S.; Songca, S.P. Biopolymers-Application in Nanoscience and Nanotechnology. Recent Adv. Biopolym. 2016, 1, 47-66.

67. Neves, A.C.C.; Rohen, L.A.; Mantovani, D.P.; Carvalho, J.P.R.G.; Vieira, C.M.F.; Lopes, F.P.D.; Simonassi, N.T.; Luz, F.S.D.; Monteiro, S.N. Comparative mechanical properties between biocomposites of Epoxy and polyester matrices reinforced by hemp fiber. J. Mater. Res. Technol. 2020, 9, 1296-1304. [CrossRef]

68. Díez-Pascual, A.M. Synthesis and Applications of Biopolymer Composites. Int. J. Mol. Sci. 2019, 20, 2321. [CrossRef] [PubMed]

69. Pilla, S. Engineering Applications of Bioplastics and Biocomposites-An Overview. In Handbook of Bioplastics and Biocomposites Engineering Applications; Pilla, S., Ed.; John Wiley \& Sons Inc.: Hoboken, NJ, USA; Scrivener Publishing LLC: Salem, MA, USA, 2011.

70. Vahabi, H.; Rastin, H.; Movahedifar, E.; Antoun, K.; Brosse, N.; Saeb, M.R. Flame Retardancy of Bio-Based Polyurethanes: Opportunities and Challenges. Polymers 2020, 12, 1234. [CrossRef]

71. Reichert, C.L.; Bugnicourt, E.; Coltelli, M.-B.; Cinelli, P.; Lazzeri, A.; Canesi, I.; Braca, F.; Martínez, B.M.; Alonso, R.; Agostinis, L.; et al. Bio-Based Packaging: Materials, Modifications, Industrial Applications and Sustainability. Polymers 2020, $12,1558$. [CrossRef]

72. Singhvi, M.; Gokhale, D. Biomass to biodegradable polymer (PLA). RSC Adv. 2013, 3, 13558-13568. [CrossRef]

73. Iwata, T. Biodegradable and Bio-Based Polymers: Future Prospects of Eco-Friendly Plastics. Angew. Chem. Int. Ed. 2015, 54, 3210-3215. [CrossRef]

74. RameshKumar, S.; Shaiju, P.; O'Connor, K.E. Bio-based and biodegradable polymers-Tate-of-the-art, challenges and emerging trends. Curr. Opin. Green Sustain. Chem. 2020, 21, 75-81. [CrossRef]

75. Kumar, R.; Ha, S.K.; Verma, K.; Tiwari, S.K. Recent progress in selected bio-nanomaterials and their engineering applications: An overview. J. Sci. Adv. Mater. Devices 2018, 3, 263-288. [CrossRef]

76. Jiang, T.; Duan, Q.; Zhu, J.; Liu, H.; Yu, L. Starch-based Biodegradable Materials: Challenges and Opportunities. Adv. Ind. Eng. Polym. Res. 2019, 3, 8-18. [CrossRef] 
77. Johansson, C.; Bras, J.; Mondragon, I.; Nechita, P.; Plackett, D.; Šimon, P.; Svetec, D.G.; Virtanen, S.; Baschetti, M.G.; Breen, C.; et al. Renewable fibers and bio-based materials for packaging applications-A review of recent developments. BioResources 2012, 7, 2506-2552. [CrossRef]

78. Pandey, J.K.; Pratheep Kumar, A.; Misra, M.; Mohanty, A.K.; Drzal, L.T.; Singh, R.P. Recent advances in biodegradable nanocomposites. J. Nanosci. Nanotechnol. 2005, 5, 497-526. [CrossRef] [PubMed]

79. Fahma, F.; Sunarti, T.C.; Indriyani, S.M.; Lisdayana, N. Thermoplastic Cassava Starch-PVA Composite Films with Cellulose Nanofibers from Oil Palm Empty Fruit Bunches as Reinforcement Agent. Int. J. Polym. Sci. 2017, 2017, 2745721. [CrossRef]

80. Muhammadi, S.; Afzal, M.; Hameed, S. Bacterial polyhydroxyalkanoates-eco-friendly next generation plastic: Production, biocompatibility, biodegradation, physical properties and applications. Green Chem. Lett. Rev. 2015, 8, 56-77. [CrossRef]

81. Bugnicourt, E.; Schmid, M.; Nerney, O.M.; Wildner, J.; Smykala, L.; Lazzeri, A.; Cinelli, P. Processing and validation of wheyprotein-coated films and laminates at semi-industrial scale as novel recyclable food packaging materials with excellent barrier properties. Adv. Mater. Sci. Eng. 2013, 2013, 496207. [CrossRef]

82. Zink, J.; Wyrobnik, T.; Prinz, T.; Schmid, M. Physical, Chemical and Biochemical Modifications of Protein-Based Films and Coatings: An Extensive Review. Int. J. Mol. Sci. 2016, 17, 1376.

83. Xu, J.; Guo, B.-H. Microbial Succinic Acid, Its Polymer Poly(Butylene Succinate), and Applications. In Plastics from Bacteria; Chen, G.G.-Q., Ed.; Springer: Berlin/Heidelberg, Germany, 2010.

84. Seggiani, M.; Gigante, V.; Cinelli, P.; Coltelli, M.B.; Sandroni, M.; Anguillesi, I.; Lazzeri, A. Processing and mechanical performances of Poly(Butylene Succinate-co-Adipate) (PBSA) and raw hydrolyzed collagen (HC) thermoplastic blends. Polym. Test. 2019, 77, 105900. [CrossRef]

85. Kahve, H.I.; Ardic, M. Lipid-Based Edible Films. J. Sci. Eng. Res. 2017, 4, 86-92.

86. Ogunsona, E.; Ojogbo, E.; Mekonnen, T. Advanced material applications of starch and its derivatives. Eur. Polym. J. 2018, 108, 570-581. [CrossRef]

87. Waheed, Z.; Dong, Y. Recent Advances and Perspectives on Starch Nanocomposites for Packaging Applications. J. Mater. Sci. 2018, 53, 15319-15339. [CrossRef]

88. Marichelvam, M.K.; Jawaid, M.; Asim, M. Corn and Rice Starch-Based Bio-Plastics as Alternative Packaging Materials. Fibers $2019,7,32$.

89. Boudjema, H.L.; Bendaikha, H. Composite materials derived from biodegradable starch polymer and Atriplex halimus fibers. e-Polymers 2015, 15, 419-426. [CrossRef]

90. Lv, H.; Cui, S.; Zhang, H.; Pei, X.; Gao, Z.; Hu, J.; Zhou, Y.; Liu, Y. Crosslinked starch nanofibers with high mechanical strength and excellent water resistance for biomedical applications. Biomed. Mater. 2020, 15, 025007. [PubMed]

91. Cerqueira, J.C.; Penha, S.; Oliveira, R.S.; Lefol, L.; Guarieiro, N.; Melo, S.; Viana, J.D.; Aparecida, B.; Machado, S. Production of biodegradable starch nanocomposites using cellulose nanocrystals extracted from coconut fibers. Polimeros 2017, $27,320-329$.

92. Yu, M.; Wang, Y. Starch-based nanoparticles: Stimuli responsiveness, toxicity, and interactions with food components. Comprehens. Rev. Food Sci. Food Saf. 2021, 20, 1075-1100. [CrossRef]

93. Fazeli, M.; Keley, M.; Biazar, E. Preparation and characterization of starch-based composite films reinforced by cellulose nanofibers. Int. J. Biol. Macromol. 2018, 116, 272-280. [CrossRef] [PubMed]

94. Raveendran, P.; Fu, J.; Wallen, S.L.; Hill, C.; Carolina, N. Completely “Green” Synthesis and Stabilization of Metal Nanoparticles. J. Am. Ceram. Soc. 2003, 125, 13940-13941. [CrossRef] [PubMed]

95. Gregorová, E.; Pabst, W.; Smith, D.S.; Zivcová, Z. Thermal conductivity of porous alumina ceramics prepared using starch as a pore-forming agent. J. Eur. Ceram. Soc. 2009, 29, 347-353. [CrossRef]

96. Mansourighasri, A.; Muhamad, N.; Sulong, A.B. Processing titanium foams using tapioca starch as a space holder. J. Mater. Process. Tech. 2012, 212, 83-89. [CrossRef]

97. Alves, H.M.; Tarì, G.; Fonseca, A.T.; Ferreira, J.M.F. Processing of Porous Cordierite Bodies by starch consolidation. Mater. Res. Bull. 1998, 33, 1439-1448. [CrossRef]

98. Davis, J.B.; Kristoffersson, A.; Carlstro, E.; Clegg, W.J. Fabrication and Crack Deflection in Ceramic Laminates with Porous Interlayers. J. Am. Ceram. Soc. 2000, 74, 2369-2374. [CrossRef]

99. He, F.; Zhao, D. Preparation and Characterization of a New Class of Starch-Stabilized Bimetallic Nanoparticles for Degradation of Chlorinated Hydrocarbons in Water. Environ. Sci.Technol. 2005, 39, 3314-3320. [CrossRef]

100. Sami, A.J.; Khalid, M.; Iqbal, S.; Afzal, M.; Shakoori, A.R. Synthesis and Application of Chitosan- Starch Based Nanocomposite in Wastewater Treatment for the Removal of Anionic Commercial Dyes. Pak. J. Zool. 2017, 49, 21-26. [CrossRef]

101. Woranuch, S.; Pangon, A.; Puagsuntia, K.; Subjalearndee, N. Starch-based and multi-purpose nanofibrous membrane for high efficiency nanofiltration. RSC Adv. 2017, 7, 35368-35375. [CrossRef]

102. Mirab, F.; Eslamian, M.; Bagheri, R. Fabrication and characterization of a starch-based nanocomposite scaffold with highly porous and gradient structure for bone tissue engineering. Biomed. Phys. Eng. Express 2018, 4, 055021. [CrossRef]

103. Fan, X.; Keynton, R.S. Fabrication and characterization of biopolymer fibers for 3D oriented microvascular structures. J. MicroMech. MicroEng. 2019, 29, 083003. [CrossRef]

104. Odeku, O.A.; Akinwande, B.L. Effect of the mode of incorporation on the disintegrant properties of acid modified water and white yam starches. Saudi Pharm. J. 2012, 20, 171-175. [CrossRef] [PubMed] 
105. Odeku, O.A.; Schmid, W.; Picker-freyer, K.M. Material and tablet properties of pregelatinized (thermally modified ) Dioscorea starches. Eur. J. Pharm. Biopharm. 2008, 70, 357-371. [CrossRef] [PubMed]

106. Santander-ortega, M.J.; Stauner, T.; Loretz, B.; Ortega-vinuesa, J.L.; Bastos-gonzález, D.; Wenz, G. Nanoparticles made from novel starch derivatives for transdermal drug delivery. J. Control. Release 2010, 141, 85-92. [CrossRef] [PubMed]

107. Vijaya, A.; Mariadoss, A.; Saravanakumar, K.; Sathiyaseelan, A. Folic acid functionalized starch encapsulated green synthesized copper oxide nanoparticles for targeted drug delivery in breast cancer therapy. Int. J. Biol. Macromol. 2020, 164, $2073-2084$. [CrossRef]

108. Ju, B.; Yan, D.; Zhang, S. Micelles self-assembled from thermoresponsive 2-hydroxy-3-butoxypropyl starches for drug delivery. Carbohydr. Polym. 2012, 87, 1404-1409. [CrossRef]

109. Odeku, O.A. Potentials of tropical starches as pharmaceutical excipients: A review. Starch Stärke 2013, 65, 89-106. [CrossRef]

110. Odeku, O.A.; Picker-freyer, K.M. Characterization of acid modified Dioscorea starches as direct compression excipient. Pharm. Dev. Technol. 2009, 14, 259-270. [CrossRef]

111. Guan, Y.; Qian, L.; Xiao, H.; Zheng, A. Preparation of novel antimicrobial-modified starch and its adsorption on cellulose fibers: Part I. Optimization of synthetic conditions and antimicrobial activities. Cellulose 2008, 15, 609-618. [CrossRef]

112. Khalid, S.; Yu, L.; Feng, M.; Meng, L.; Bai, Y.; Ali, A.; Liu, H.; Chen, L. Development and characterization of biodegradable antimicrobial packaging fi lms based on polycaprolactone, starch and pomegranate rind hybrids. Food Packag. Shelf Life 2018, 18, 71-79. [CrossRef]

113. Syafiq, R.; Sapuan, S.M.; Zuhri, M.Y.M.; Ilyas, R.A.; Nazrin, A.; Sherwani, S.F.K. Antimicrobial Activities of Starch-Based Biopolymers and Biocomposites Incorporated with Plant Essential Oils: A Review. Polymers 2020, 12, 2403. [CrossRef] [PubMed]

114. Pelissari, F.M.; Grossmann, M.V.; Yamashita, F.; Pineda, E.A.G. Antimicrobial, Mechanical, and Barrier Properties of Cassava Starch-Chitosan Films Incorporated with Oregano Essential Oil. J. Agric. Food Chem. 2009, 57, 7499-7504. [CrossRef] [PubMed]

115. Li, X.; Min, J.; Chen, Y.; Zhao, G. Antimicrobial and physical properties of sweet potato starch films incorporated with potassium sorbate or chitosan. Food Hydrocoll. 2010, 24, 285-290. [CrossRef]

116. Ziaee, Z.; Qian, L.; Guan, Y.; Fatehi, P.; Xiao, H. Antimicrobial/Antimold Polymer-Grafted Starches for Recycled Cellulose Fibers. J. Biomater. Sci. 2012, 37-41. [CrossRef] [PubMed]

117. Kim, J.R.; Netravali, A.N. Self-healing starch-based 'green' thermoset resin. Polymer 2017. [CrossRef]

118. Zhu, Z.; Xia, K.; Xu, Z.; Lou, H.; Zhang, H. Starch Paper-Based Triboelectric Nanogenerator for Human Perspiration Sensing. Nanoscale Res. Lett. 2018, 13, 365. [CrossRef]

119. Jeong, H.; Baek, S.; Han, S.; Jang, H.; Kim, S.H. Novel Eco-Friendly Starch Paper for Use in Flexible, Transparent, and Disposable Organic Electronics. Adv. Funct. Mater. 2018, 28, 1704433. [CrossRef]

120. Cyprych, K.; Sznitko, L.; Mysliwiec, J. Starch: Application of biopolymer in random lasing. Org. Electron. 2014, 15, $2218-2222$. [CrossRef]

121. Chen, G.; Zhu, P.; Kuang, Y.; Liu, Y.; Lin, D.; Peng, C. Durable superhydrophobic paper enabled by surface sizing of starch-based composite films. Appl. Surf. Sci. 2017, 409, 45-51. [CrossRef]

122. Sun, B.; Xie, G.; Jiang, Y.; Li, X. Comparative CO2-Sensing Characteristic Studies of PEI and PEI / Starch Thin Film Sensors. Energy Procedia 2011, 12, 726-732. [CrossRef]

123. Khachatryan, G.C.; Khachatryan, K. Starch based nanocomposites as sensors for heavy metals-Detection of $\mathrm{Cu}^{2+}$ and $\mathrm{Pb}^{2+}$ ions. Int. AgroPhys. 2019, 33. [CrossRef]

124. Liu, B.; Xu, H.; Zhao, H.; Liu, W.; Zhao, L.; Li, Y. Preparation and characterization of intelligent starch/PVA films for simultaneous colorimetric indication and antimicrobial activity for food packaging applications. Carbohydr. Polym. 2016, 157, 642-849. [CrossRef] [PubMed]

125. Vasileva, P.; Alexandrova, T.; Karadjova, I. Application of Starch-Stabilized Silver Nanoparticles as a Colorimetric Sensor for Mercury (II) in $0.005 \mathrm{~mol} / \mathrm{L}$ Nitric Acid. J. Chem. 2017, 2017, 6897960. [CrossRef]

126. Fonseca, L.M.; Radünz, M.; Santos, C.; Silva, F.T.; Camargo, T.M.; Bruni, G.P. Electrospun potato starch nanofibers for thyme essential oil encapsulation: Antioxidant activity and thermal resistance. J. Sci. Food Agric. 2020, 100, 4263-4271. [CrossRef] [PubMed] 